\title{
Strategic commitment and cooperation in experimental games of strategic complements and substitutes
}

Citation for published version (APA):

Embrey, M. S., Mengel, F., \& Peeters, R. J. A. P. (2012). Strategic commitment and cooperation in experimental games of strategic complements and substitutes. METEOR, Maastricht University School of Business and Economics. METEOR Research Memorandum No. 051 https://doi.org/10.26481/umamet.2012051

Document status and date:

Published: 01/01/2012

DOI:

10.26481/umamet.2012051

Document Version:

Publisher's PDF, also known as Version of record

Please check the document version of this publication:

- A submitted manuscript is the version of the article upon submission and before peer-review. There can be important differences between the submitted version and the official published version of record.

People interested in the research are advised to contact the author for the final version of the publication, or visit the DOI to the publisher's website.

- The final author version and the galley proof are versions of the publication after peer review.

- The final published version features the final layout of the paper including the volume, issue and page numbers.

Link to publication

\footnotetext{
General rights rights.

- You may freely distribute the URL identifying the publication in the public portal. please follow below link for the End User Agreement:

www.umlib.nl/taverne-license

Take down policy

If you believe that this document breaches copyright please contact us at:

repository@maastrichtuniversity.nl

providing details and we will investigate your claim.
}

Copyright and moral rights for the publications made accessible in the public portal are retained by the authors and/or other copyright owners and it is a condition of accessing publications that users recognise and abide by the legal requirements associated with these

- Users may download and print one copy of any publication from the public portal for the purpose of private study or research.

- You may not further distribute the material or use it for any profit-making activity or commercial gain

If the publication is distributed under the terms of Article $25 \mathrm{fa}$ of the Dutch Copyright Act, indicated by the "Taverne" license above, 
Matthew Embrey, Friederike Mengel, Ronald Peeters

Strategic commitment and cooperation in experimental games of strategic complements and substitutes

RM/12/051

\section{METEOR}

Maastricht University School of Business and Economics 


\title{
Strategic commitment and cooperation in experimental games of strategic complements and substitutes*
}

\author{
Matthew Embrey ${ }^{\dagger} \quad$ Friederike Menge $\mathrm{l}^{\ddagger}, \S \quad$ Ronald Peeters $₫$
}

October 2012

\begin{abstract}
We study the impact of strategic commitment on cooperation in indefinitely repeated games of strategic substitutes (Cournot) and complements (Bertrand) using laboratory experiments. Overall, strategic commitment has no effect on cooperation with strategic substitutes and a negative one with strategic complements. In the absence of strong strategic commitment, we find more cooperation in the complements game than in the substitutes game. However, when subjects are more committed to initial plans, a higher level of cooperation is achieved with strategic substitutes. These results cannot be explained by standard risk-dominance or renegotiation considerations, but are consistent with a notion of fear of miscoordination based on minmax regret.
\end{abstract}

JEL classification codes: C73, C92, D43

Keywords: strategic commitment, cooperation, repeated games, complements vs. substitutes, fear of miscoordination

*We thank Jose Apesteguia, Pedro Dal Bó, Guillaume Fréchette, Hans Theo Normann as well as seminar participants in Düsseldorf, Maastricht (BEElab meeting), New York (ESA 2012) and Vienna for valuable comments and the Netherlands Organisation for Scientific Research (NWO) and the European Union for support.

${ }^{\dagger}$ Department of Economics, Maastricht University, PO Box 616, 6200 MD Maastricht, The Netherlands. E-mail: m.embrey@maastrichtuniversity.nl

${ }^{\ddagger}$ Department of Economics, University of Essex, Wivenhoe Park, CO4 3SQ, United Kingdom. E-mail: fr.mengel@gmail.com

$\S^{\S}$ Department of Economics, Maastricht University, PO Box 616, 6200 MD Maastricht, The Netherlands.

${ }^{\top}$ Department of Economics, Maastricht University, PO Box 616, 6200 MD Maastricht, The Netherlands. E-mail: r.peeters@maastrichtuniversity.nl 


\section{Introduction}

By strategic commitment, we refer to the extent to which players in repeated games can, either unilaterally or bilaterally, revise their strategies during the course of play. Strategic commitment plays an important role in many situations of interest. Corporations need to determine the extent to which they wish to regulate franchises "top down" or to allow revisions to, for example, pricing strategies in response to local market conditions. ${ }^{1}$ Policy makers and regulators can influence the possibility of orchestrated strategy revisions, including renegotiation, via legal restrictions on meetings and agreements between market participants. Some instances of antitrust legislation provide good examples of such policies (see, for example, McCutcheon, 1997).

The role of strategic commitment has not been given much attention in the literature on repeated games thus far. In particular, it plays no role in (subgame perfect) Nash equilibrium. This concept has been refined in the renegotiation literature by focusing on one particular aspect of strategic commitment, namely the possibility that some paths may be renegotiated at a later date should they be reached. This can affect equilibria where the threat of punishment tomorrow is used to sustain more cooperative behavior today. Loosely speaking, if players anticipate renegotiation of such punishment paths, then punishment may no longer be credible and, as a consequence, collusion no longer sustainable.

This paper studies the impact of strategic commitment on cooperative behavior, referred to as collusion, in infinitely repeated games. We do this by means of a laboratory experiment where the level of strategic commitment is exogenously varied across treatments. Our experiment systematically varies the ease with which participants can revise their strategy during the course of a repeated game, isolating the effect of such strategic commitment while keeping other, potentially confounding, factors constant, such as the size of the stakes, the strategy sets, the number of players and the incentives to deviate. Hence, strategic commitment in our study does not entail moving from simultaneous to sequential games, nor moving from "bigger" to "smaller" strategy spaces. In addition, our design elicits information about the strategies participants use in the repeated game, allowing us to define and identify changes in strategy and observe intended behavior off the realized outcome path. Since different refinements for indefinitely repeated games entail different predictions on how increasing the level of strategic commitment affects collusion, our experiment is able to discriminate between these. In particular, renegotiation proofness predicts a weak increase in collusion as commitment increases, while a notion of "fear of miscoordination", that we define precisely below, predicts a weak decrease in collusion as commitment increases.

In the experiment, participants play an indefinitely repeated game where the stage game is

\footnotetext{
${ }^{1}$ McDonalds typically allows local restaurants to unilaterally deviate from pricing strategies (nationwide commercials involving prices usually have the caveat "in participating restaurants" attached). Ikea does not allow local stores in Germany to price articles higher than indicated in the nationwide catalogue. Lower prices are allowed in some cases.
} 
either a game of strategic substitutes or of strategic complements. The stage games are derived from equivalent linear duopoly games (Cournot and Bertrand respectively) and reduced to symmetric, normal-form games in which both players have four actions to choose from. The demand systems and action sets are chosen so that the resulting payoff matrices are as close as possible: they have identical diagonal elements (including the collusion and Nash outcomes), as well as identical temptation and sucker payoffs. The games primarily differ in the location of the deviation action. In the substitutes game, the deviation action is less cooperative than the Nash action, while in the complements game it is more cooperative than the Nash action.

At the beginning of a supergame, participants program a strategy by choosing an initial action choice and a dynamic response machine, which specifies a recommended action in response to their rival's previous action choice. Four levels of strategic commitment determine the extent to which participants are committed to their programmed strategies. These levels are labelled as the strong, unilateral, bilateral and hot variations. In all variations, participants can deviate from their recommendation using one-shot deviations. This possibility is included so that participants have the full strategy space of the repeated game available. In the first three variations, such a deviation comes at a small cost; in the hot treatment, it is costless. Strategic commitment differs across treatments as follows. In the unilateral and bilateral variations, dynamic responses can also be modified at a small cost. In the unilateral variation, this modification can be done without explicit consent of one's rival; in the bilateral variation, explicit consent is required. In the strong commitment variation, machines cannot be modified. The main variations for considering the impact of strategic commitment on cooperation are the strong and unilateral variations. The purpose of the bilateral variation which in terms of the level of commitment, should be positioned between the main variations - is to further investigate the possible functioning of renegotiation. The hot variation is used to empirically evaluate (by comparing it to the unilateral variation) whether the small costs we impose on one-shot deviations and machine changes distort our participants' choice of strategies.

We find that strategic commitment has no effect on cooperation under strategic substitutes, yet has a significant, negative effect under strategic complements. The second effect is large enough to reverse the ranking of collusion rates between interaction types: there is more cooperation under strategic substitutes when strategic commitment is weak, while the opposite is true when strategic commitment is strong. Neither standard risk dominance nor considerations of renegotiation can explain these results. Given the large multiplicity of equilibria in these games, it is intuitive that fear of miscoordination might play an important role. We define a notion of "fear of miscoordination", based on minmax regret, and show that it yields predictions consistent with our main results.

In terms of the strategies participants use, we find that most use machines that are familiar from the literature. The most prominent machines mimic the always-Nash, myopicbest-response, tit-for-tat and Nash-reversion strategies. Participants tend to use machines 
less often the higher the "fear of miscoordination" associated with these machines. While generally "fear of miscoordination" tends to have more bite under strategic complements, there is another crucial difference between complements and substitutes: Identifying defectors is more ambiguous under strategic complements than under substitutes, since partial collusion is also the action associated with deviation under the former.

The paper is organized as follows: Section 2 reviews related literature; Section 3 outlines the experimental design and states our conjectures; Section 4 covers the data analysis; Section 5 provides a discussion of the results and contrasts alternative explanations, while a final section concludes. The appendices contain additional complementary material.

\section{Related literature}

Our research bridges two literatures that have each received some attention in recent years but have, to the best of our knowledge, not been brought together: namely, strategic commitment (including renegotiation) and the type of strategic interaction (strategic substitutes versus complements). The first two subsections relate our work to prior research in each of these areas. The third subsection relates our work to the experimental literature on strategy elicitation in infinitely repeated games.

\subsection{Strategic commitment}

Much of the theoretical literature on strategic commitment deals with renegotiation. The theory of renegotiation argues that, in some cases, collusion may not be sustainable by strategies, such as grim-trigger, that include punishment paths that agents would want to "renegotiate" should they be reached. This makes such punishments no longer credible. That is, if there are possibilities for renegotiation, there should be weakly less collusion under weak commitment than under strong commitment, where such renegotiation is not possible. The two most well-known concepts of renegotiation theory are the weak renegotiation proof equilibrium of Farrell and Maskin (1989) and the consistent bargaining equilibrium of Abreu, Pearce, and Stachetti (1993). As long as future payoffs are not discounted "too much", collusion is weakly renegotiation proof under both Cournot and Bertrand competition (Aramendia, Larrea, and Ruiz, 2005).

McCutcheon (1997) applies the idea of costly renegotiation to antitrust legislation on meetings between rivals to discuss prices. The idea is that, if meeting is costly, but not prohibitively so, then firms may be willing to meet to initiate collusion, but not to renegotiate punishment paths. As a consequence, antitrust legislation, without sufficient sanctioning, may actually facilitate collusion. ${ }^{2}$ This finding, together with the papers mentioned in the former

\footnotetext{
${ }^{2}$ There is a recent strand of the experimental literature on cooperation/collusion explicitly investigating the role of communication. Fonseca and Normann (2012), Andersson and Wengström (2012) and Cooper and Kuhn (2012) all study renegotiation with communication and find mixed results as to whether communication, and the timing of communication, leads to more collusion or not.
} 
paragraph, will form the basis of one of our alternative conjectures.

There is less experimental research on strategic commitment. Mengel and Peeters (2011) have a "semi-hot" treatment (hot but with small costs) and a "strong commitment" treatment in a study comparing contributions by partners and strangers in a repeated public good game. Their reason for eliciting strategies is that it controls for path-dependencies (impact of initial states) in this comparison. Huck, Müller, and Normann (2002) study commitment in a twostage Cournot duopoly, where players can endogenously choose to commit to a quantity in the first stage or to postpone their strategic decision to the second stage. As mentioned earlier, we do not study such endogenous commitment choices, where players turn simultaneous move games into sequential games. There is also a literature comparing the so-called "strategy method" with "hot" treatments in sequential games. We will survey some of this literature in Subsection 2.3. To the best of our knowledge, the effect of strategic commitment in indefinitely repeated games has not been the subject of an experimental study before.

\subsection{Type of strategic interaction}

The concepts of strategic substitutes and complements were introduced by Bulow, Geneakoplos, and Klemperer (1985). There is little theory on the impact of the type of strategic interaction on collusion. According to the standard theory of infinitely repeated games, collusion is sustainable under both types of interaction whenever future payoffs are not discounted "too much" (see, for example, Mailath and Samuelson, 2005). The two games in our experiment are designed so that the minimal discount factors required to sustain collusion are the same in both games.

Potters and Suetens (2009) study collusion in a laboratory experiment using finitely repeated games of strategic substitutes and complements. With a design that varies whether the stage game is price or quantity competition and whether duopolists' actions exert a positive or

negative externality on their rivals, they find more cooperation when actions exhibit strategic complementarities. As all their treatments are within a framework of "hot" decision making, their results are best compared to our unilateral or hot variations where the level of strategic commitment is low. As will be seen, our results with a low level of strategic commitment confirm theirs. However, when the level of strategic commitment is high, we find the opposite is true: there is more collusion with strategic substitutes. Consequently, whether strategic complementarity or substitutability is more conducive to collusion appears to depend on the level of strategic commitment. In addition, our data on the dynamic responses of participants give us information on the strategies being used, providing further insight into the underlying reasons for the observed treatment rankings. 


\subsection{Strategy elicitation in infinitely repeated games}

A prominent study of strategies in an infinitely repeated game, with strong commitment, is the Axelrod tournament (Axelrod, 1984). ${ }^{3}$ In our study we are primarily interested in which strategies people actually use, and not in which strategies perform best in such contests. Those questions generally have different answers, since other motives than pure performance can play a role and impact behavior. We decided not to do a tournament or simulation study since those formats are not well suited to studying renegotiation or strategic commitment more generally.

Selten, Mitzkewitz, and Ulrich (1997) is an early example of strategy elicitation in a repeated-game environment. They let participants of a student seminar program strategies for a finitely (3-period) repeated prisoner's dilemma game under "strong commitment conditions" after a "hot" phase that lasted 3 periods as well. Their main finding is that "subjects first select an 'ideal point', a cooperative goal based on fairness criteria, and then design a 'measure for measure policy' that reciprocates movements to the ideal point or away from it".

In a recent study, Dal Bó and Fréchette (2011b) elicit strategies in an infinitely repeatedgame environment. They consider, as we do, one-period histories and ask participants to specify choices in the $2 \times 2$ prisoner's dilemma game for each of the 4 possible one-period histories. In their design, the programmed strategy is initially irrelevant for choices as participants choose as in a "hot" treatment. After 20 minutes, the strategy takes over and, hence, from then on there is "strong commitment". Their main findings are that participants use strategies we are familiar with from the literature (such as tit-for-tat), and that behavior in the "hot" phase and behavior implied by the strategies programmed in the "strong commitment phase" are not significantly different. Their study relates most closely to our treatments with strategic substitutes, and their findings are in line with ours for this case: participants use strategies we know from the literature, the distribution of strategies do not significantly differ across different levels of strategic commitment and there are no significant differences in (implied) behavior between the "hot" and "strong commitment" cases.

The strategies participants could programme in our experiment differ from those in Dal Bó and Fréchette (2011b). This difference is a consequence of the $4 \times 4$ stage games we use a setting with less than four actions would not have allowed a clean distinction between substitutes and complements. With 4 actions, we decided not to ask participants to program a response for each of the 16 possible outcomes from the previous stage, but instead only for the 4 possible action choices of their rival. Such a strategy elicitation method is also used in Mengel and Peeters (2011). Unlike Dal Bó and Fréchette (2011b), they find some differences between a strong commitment case and a "costly hot" case, suggesting that whether or not strategic commitment has an effect on behavior depends, apart from the mechanism used to elicit strategies, on the type of game (strategic substitutes or complements) considered.

\footnotetext{
${ }^{3}$ See also the many subsequent studies, for example Nowak and Sigmund (1990).
} 
A number of studies aim explicitly to test the validity of the strategy method. The results from this literature are quite mixed. For example, Brosig and Yang (2003) find significant differences between a strategy method treatment and a hot treatment in bargaining games. In contrast, Brandts and Charness (2000) do not find significant differences in a prisoners' dilemma game and a hawk-dove game. As none of these studies concern repeated games, and it is hard to interpret their strategy methods as implying more strategic commitment, we implemented a hot treatment for benchmarking purposes.

\section{The experiment}

Our $4 \times 2$ design has four levels of strategic commitment and two types of strategic interaction. This section provides a detailed specification of the treatment variables and how the different levels/types were implemented in the laboratory, the experimental procedures and the conjectures that follow from the predictions of different theories.

\subsection{Design}

Participants play one of two possible games that differ in the type of strategic interaction: strategic substitutes or strategic complements. Table 1 presents the payoff-matrices of the two stage games (with ECU being the prevailing currency).

\begin{tabular}{|c|c|c|c|c|}
\hline & A & B & C & $\mathrm{D}$ \\
\hline 4 & 43,43 & 31,51 & 25,52 & 23,54 \\
\hline & 51,31 & 36,36 & 32,40 & 29,38 \\
\hline & 52,25 & 40,32 & 33,33 & 31,32 \\
\hline & 54,23 & 38,29 & 32,31 & 30,30 \\
\hline
\end{tabular}

Strategic substitutes.

\begin{tabular}{l|c|c|c|c|} 
& \multicolumn{1}{c}{$\mathrm{A}$} & \multicolumn{1}{c}{$\mathrm{B}$} & \multicolumn{1}{c}{$\mathrm{C}$} & \multicolumn{1}{c}{$\mathrm{D}$} \\
\cline { 2 - 5 } $\mathrm{A}$ & 43,43 & 23,54 & 14,52 & 7,47 \\
\cline { 2 - 5 } $\mathrm{B}$ & 54,23 & 36,36 & 32,40 & 28,37 \\
$\mathrm{n} \mathrm{C}$ & 52,14 & 40,32 & 33,33 & 31,32 \\
\cline { 2 - 5 } $\mathrm{D}$ & 47,7 & 37,28 & 32,31 & 30,30 \\
\cline { 2 - 5 } & & & &
\end{tabular}

Strategic complements.

Table 1: The two stage games in the experiment.

The structure and payoffs of the games are designed so that, while each game has a natural duopoly analogue, the two are as identical as possible. To provide this analogue, the complements game is a discretized version of a differentiated-goods linear Bertrand duopoly and the substitutes game a discretized version of a differentiated-goods linear Cournot duopoly. In both cases, the duopolists produce differentiated-goods that are product substitutes. To ensure a fair comparison across games, the underlying duopoly games were calibrated so that the majority of payoffs for key action pairs are identical across games: First, the Nash equilibrium payoffs that result from both players playing action $\mathrm{C}$ are identical. Second, the joint payoff maximizing payoffs that result from both choosing action A are identical. Third and fourth, the optimal deviation against the co-player playing action $\mathrm{A}$, which requires playing action $\mathrm{B}$ in the complements game and action $\mathrm{D}$ in the substitutes game, yields the same payoff for the defector and the sucker across games. Fifth and sixth, the remaining actions 
in the games, action D for the complements game and action B for the substitutes game, are such that all diagonal elements are identical across games. ${ }^{4}$

The crucial difference between the two games is the location of the optimal deviation against the co-player playing the joint payoff maximizing action, which is action $\mathrm{B}$ with strategic complements and action D with strategic substitutes. Consequently, the optimal deviation action is located between the collusive action (A) and the Nash action (C) in the complements game, whereas it is located beyond the Nash action in the substitutes game. In terms of the underlying Bertrand and Cournot duopolies, these deviations correspond to, respectively, a small price undercut and an increase in supply beyond the competitive level. The difference in the location of these actions is the primary difference between the games; a difference that will prove to have a significant interaction with the level of strategic commitment. For convenience, we will refer to the actions A, B, C and D as respectively Collusion, Dev.SC, Nash and Dev.SS.

By construction, collusion is not an equilibrium outcome of these one-shot games. Infinite repetition of a game, with future payoffs being exponentially discounted, introduces equilibria in which players can sustain collusion by providing intertemporal incentives to cooperate. To mimic this environment in the laboratory, participants play an indefinitely repeated game, where, after a stage has been played, the super-game is randomly terminated using a fixed continuation probability equal to the discount factor. ${ }^{5}$ The continuation probability is chosen so that collusion can be sustained (in a Nash equilibrium) in either game via well-know strategies such as grim-trigger and tit-for-tat. The minimal discount factor needed for those strategies to sustain collusion is the same in both games and the chosen continuation probability of $\delta=7 / 8$ is above this level.

At the beginning of a repeated game, participants are asked to specify an intended strategy. This strategy consists of an initial action, to be played in the first stage, and a programmed machine, which recommends at each later stage an action conditional on their co-player's action in the previous stage. The machine is denoted by a quadruple $z^{A} z^{B} z^{C} z^{D}$ specifying which action $z^{k} \in\{A, B, C, D\}$ the machine is programmed to play if the opponent has chosen action $k \in\{A, B, C, D\}$ in the previous stage. An intended strategy is denoted by $z^{\emptyset}-z^{A} z^{B} z^{C} z^{D}$, where the first element refers to the initial action choice. The most general strategy one can formulate in such a repeated game maps any possible history of observed action profiles into actions. In this design, however, participants' intended strategies are restricted so that actions can only be conditioned on their co-player's action in the previous stage. Some examples of familiar strategies that can be programmed are: unconditional cooperation (A-AAAA), tit-for-tat (A-ABCD), (forgiving) Nash reversion (A-ACCC), and

\footnotetext{
${ }^{4}$ After rounding the payoffs to numbers, one unit of payoff was added to some payoffs in order to avoid degeneracies that are caused by rounding. This is done in such a way that games become even more similar: for instance, this led to the box formed by actions B and C and that formed by actions $\mathrm{C}$ and $\mathrm{D}$ being identical across games.

${ }^{5}$ This approach follows Roth and Murnighan (1978).
} 
always Nash (C-CCCC). A well-known machine that cannot be programmed is grim-trigger, since the ACCC-machine that comes closest reverts to cooperation if the co-player chooses to cooperate in some stage following a deviation.

In all treatments, participants are allowed to take an action that differs from the one recommended by their machine. Such changes are referred to as one-shot deviations. In addition, it is possible for participants to modify their machines in some treatments. Consequently, more general strategies, such as grim-trigger, become feasible to implement, either via a machine modification (for example, from ADDD to DDDD) or via a series of one-shot deviations. Allowing for one-shot deviations ensures that the full strategy space is available for participants in all treatments. The ease with which machine changes can be made determines the level of commitment to intended strategies, and is our second treatment variation.

Participants face the most commitment to their intended strategies in the treatments labeled strong. Here, participants keep their machines for the entire duration of the repeated game, and can only deviate from the recommendations of their machines via one-shot deviations. The least amount commitment comes in the treatments labeled unilateral. Here, participants can modify their machines after any stage of the repeated game. In terms of the level of strategic commitment, the third variation - labeled bilateral - ranks in between the other two. Here, participants can modify their machines if and only if consent to a modification has been given by their co-player.

To provide participants with an incentive to program their machines (strategies) carefully, one-shot deviations and machine modifications have a small cost associated with them. Each one-shot deviation costs 3 ECU; each machine modification 1 ECU, irrespective of the number of elements of the machine that are changed. Choosing the costs in such a manner we hoped to ensure that playing with a poorly programmed strategy is much more costly under strong commitment (where one needs to rely on one-shot deviations) than under weak commitment where machine changes are possible.

To verify that behavior was not unduly affected by the costs placed on implementing more general strategies, a fourth treatment variation - labeled hot - was implemented. In this variation, the cost of one-shot deviations was set to zero, resulting in no monetary incentive for participants to stick to the recommendation of their machine. This treatment gives the same degree of strategic flexibility as the unilateral variation, except now the flexibility comes for free. Any differences between the hot and unilateral variation would indicate that costs for one-shot deviations and machine changes might be distorting behavior. As is shown in Appendix B, behavior in these two treatment variations is very similar in terms of the amount of collusion, the level of joint profits, the distribution of machines used by participants and the dynamics of behavior within and across matches. 


\subsection{Procedures}

The experiment was conducted in the BEElab at Maastricht University during OctoberDecember 2011. 352 students were recruited using Orsee (Greiner, 2004) and participated in one of the eight treatments. ${ }^{6}$ During each session, three matching groups were run in parallel on separate z-Tree servers (Fischbacher, 2007). Sessions lasted an hour and a half on average, including a twenty minute instruction period. ${ }^{7}$ On average participants earned between 12.60 and 15.30 Euro for their participation. ${ }^{8}$

For the strong, unilateral and bilateral commitment variations, six matching groups were run; for the hot variations, four matching groups were run. Each matching group comprised eight participants that all played the repeated game (of the same treatment) ten times. At the beginning of a match, as a single repeated game is referred to, participants within a matching group were randomly paired. At the end of a session, participants were paid in cash according to the amount of ECUs they earned in one randomly drawn match.

Participants were fully informed about all details of the decision task, the environment and procedures in the experimental instructions (see Appendix A for an example of the instructions). Participants were never informed of the machine employed by other participants, but instead observed the history of play. That is, after every stage they were updated about their own and the action choices of the person they were matched with from the previous stage and the resulting payoffs.

For all members in a matching group, any given match consisted of the same number of stages, but this number changed across matches. Across matching groups this sequence of match-lengths differed. However, to facilitate a good comparison between treatments, the same sequences were used for the different matching groups of each treatment. Table 2 presents these sequences for the different matching groups that are indexed in order of increasing total number of stages.

\subsection{Conjectures}

The first series of conjectures concern the predictions of existing theories for the impact of strategic commitment on collusion. The first conjecture is formulated on the basis of standard (subgame perfect) Nash equilibrium. By design, trigger strategies can sustain collusion in all treatments - even the necessary and sufficient conditions on discount factors (continuation probabilities) for trigger strategies to support collusion are identical for all levels of commitment. Hence, there should be no effect of strategic commitment on collusion.

\footnotetext{
${ }^{6}$ Other than the treatments mentioned we did not conduct any additional treatments. We conducted one pilot session with a 6x6 game, after which we decided to switch to a $4 \mathrm{x} 4$ game to reduce complexity for participants and hence the duration of the experiment. Other than this session we did not conduct any other pilot studies.

${ }^{7}$ Due to the randomness in the length of the matches, subjects were recruited for up to 2 hours. No session lasted longer than 1 hour and 45 minutes.

${ }^{8}$ See Table 3 for a detailed summary of the treatments.
} 


\begin{tabular}{|c|c|c|c|c|c|c|c|c|c|c|c|}
\hline \multirow{2}{*}{$\begin{array}{r}\text { Matching } \\
\text { Group }\end{array}$} & \multicolumn{10}{|c|}{ Match } & \multirow[b]{2}{*}{ Total } \\
\hline & 1 & 2 & 3 & 4 & 5 & 6 & 7 & 8 & 9 & 10 & \\
\hline 1 & 13 & 8 & 1 & 4 & 1 & 5 & 20 & 7 & 8 & 2 & 69 \\
\hline 2 & 1 & 4 & 3 & 4 & 15 & 18 & 15 & 6 & 2 & 2 & 70 \\
\hline 3 & 10 & 10 & 10 & 8 & 3 & 2 & 2 & 13 & 11 & 12 & 81 \\
\hline 4 & 9 & 5 & 8 & 10 & 9 & 4 & 12 & 12 & 18 & 4 & 91 \\
\hline 5 & 2 & 1 & 9 & 14 & 15 & 14 & 3 & 8 & 20 & 6 & 92 \\
\hline 6 & 6 & 4 & 6 & 8 & 3 & 11 & 8 & 26 & 19 & 7 & 98 \\
\hline
\end{tabular}

Table 2: Number of stages played in the ten matches for the six different matching groups.

Conjecture A-0 (SPNE) Strategic commitment should not have an impact on collusion (irrespective of the type of strategic interaction).

The second conjecture is based on the notion of renegotiation. While for duopolies like those considered in our paper, existing concepts of renegotiation-proofness do not rule out collusion, still a clear intuition can be derived from this literature. ${ }^{9}$ For instance, McCutcheon (1997) argues that if competitors are sufficiently committed to their strategies, we should see more collusion. The idea is that punishment paths cannot (or are too costly to) be renegotiated, making the threat of punishments credible and thus deterring prospective defectors. As a result, competitors have sufficient mutual confidence in being able to sustain collusion.

Conjecture A-1 (Renegotiation) There should be weakly less collusion in treatments with a lower level of commitment (the unilateral and bilateral variations) than in treatments with a higher level of commitment (the strong variations).

Our third conjecture is based on a notion of "fear of miscoordination". Given the large number of possible equilibria in these indefinitely repeated games, fear of miscoordination seems a particularly relevant concern and its effect may overshadow potential effects of renegotiation. In fact, as we will see fear of miscoordination ranks the treatments in exactly the opposite way compared to renegotiation. To define the fear of miscoordination for a player $i$ using repeated game strategy $s_{i}^{*}$, we use the maximal regret possible for this strategy; i.e. $\pi_{i}\left(s_{i}^{*}, s_{i}^{*}\right)-$ $\min _{s_{-i}} \pi_{i}\left(s_{i}^{*}, s_{-i}\right)$, where $\pi_{i}\left(s_{i}, s_{-i}\right)$ denotes player $i$ 's expected payoffs if she plays repeated game strategy $s_{i}$ and her opponent plays according to $s_{-i}$. Notice that this definition is formulated from the perspective of a symmetric equilibrium, which is sufficient for the purpose of this study. ${ }^{10}$ Following this definition, fear of miscoordination is always higher for strategies

\footnotetext{
${ }^{9}$ For details, see the paragraph following Conjecture B-1.

${ }^{10}$ Defining this notion for all equilibria would require knowledge about which equilibria can be supported by any given strategy. Chassang (2010) has used fear of miscoordination in a weaker sense. He studies dynamic global games and refers to fear of miscoordination as the possibility of miscoordination arising from a lack of common knowledge and in particular arbitrarily small amounts of private knowledge. His characterization of sequentially rationalizable strategies is related to risk dominance in the one-shot game and thus, unsurprisingly, quite different from ours.
} 
attempting to establish collusion than for strategies attempting to play Nash. ${ }^{11}$

In the literature it is not uncommon to assume that players choose strategies to minimize ex ante regret (see, for example, Bergemann and Schlag, 2008). We remain agnostic about the precise decision rules that players follow, and just assume that, ceteris paribus, the likelihood of using a strategy is nonincreasing in the ex ante regret - or, the fear of miscoordination - associated with that strategy. This assumption is sufficient to draw the conclusion that fear of miscoordination predicts players to be more willing to collude if there is less strategic commitment, since maximal regret is always (weakly) lower if a player can adapt her strategy than if she cannot.

Conjecture A-2 (Fear of miscoordination) There should be weakly more collusion in the treatments with a lower level of commitment (the unilateral and bilateral variations) than in the treatments with a higher level of commitment (the strong variations).

The second series of conjectures concern predictions of existing theory for the impact of type of strategic interaction on collusion. Since the stage games have been designed to minimize their differences, standard theory does not predict a difference in outcomes.

Conjecture B-0 (SPNE) and B-1 (Renegotiation) The type of strategic interaction, substitutes or complements, should not have an impact on collusion for any variation of the level of commitment.

The theory of renegotiation does not discriminate between our two games, as can be seen easily e.g. in Theorem 1 in Farrell and Maskin (1989) or Proposition 4.6.2 in Mailath and Samuelson (2005). Collusion is renegotiation proof (according to WRPE) in both games studied here, since $\max _{a_{i} \in A_{i}} \pi_{i}\left(a_{i}, D\right)=31<43$ and $\pi_{-i}(A, D)=54>43$. This leads to Conjecture B-1 above. In fact, for collusion to no longer be renegotiation-proof, for any discount rate, it is necessary to include a larger number of firms than duopoly, as well as to strengthen the concept of Farrell and Maskin (1989). See Farrell (2000) for the case of Bertrand competition and Aramendia, Larrea, and Ruiz (2005) for the case of Cournot competition.

In contrast to renegotiation, fear of miscoordination creates a wedge in the relative attractiveness of collusive strategies between the two types of strategic interaction. Assume a player chooses a strategy intended to achieve cooperation. Irrespective of whether she uses a conditionally cooperative strategy (such as A-ACCC or A-ABCD) or unconditionally cooperative strategy (such as A-AAAA), fear of miscoordination is higher with strategic complements than with strategic substitutes. ${ }^{12}$ As argued earlier, the role of fear of miscoordination should

\footnotetext{
${ }^{11}$ The maximal regret with Nash strategy $\mathrm{C}-\mathrm{CCCC}$ is $2 \frac{1}{1-\delta}$ in both games. The maximal regret from the collusive strategy $\mathrm{A}-\mathrm{ABCD}$, for example, is $36+13 \frac{\delta}{1-\delta}$ with strategic complements and $20+13 \frac{\delta}{1-\delta}$ with strategic substitutes.

${ }^{12}$ The maximal regret from the collusive strategy $\mathrm{A}-\mathrm{ABCD}$ is $36+13 \frac{\delta}{1-\delta}$ with strategic complements and $20+13 \frac{\delta}{1-\delta}$ with strategic substitutes and for the strategy A-AAAA these two values are respectively $36 \frac{1}{1-\delta}$ and $20 \frac{1}{1-\delta}$.
} 


\begin{tabular}{|c|c|c|c|c|c|c|c|c|}
\hline \multirow[b]{2}{*}{ Treatment } & \multirow[b]{2}{*}{$\begin{array}{c}\text { Matching } \\
\text { Groups }\end{array}$} & \multirow[b]{2}{*}{$\begin{array}{l}\text { Number } \\
\text { Subjects }\end{array}$} & \multirow{2}{*}{$\begin{array}{c}\text { Earnings } \\
\text { Avg. } \\
(\mathrm{EUR})\end{array}$} & \multicolumn{2}{|c|}{ Stage-Game Payoffs } & \multicolumn{3}{|c|}{ Incurred Costs } \\
\hline & & & & $\begin{array}{l}\text { Avg. } \\
\text { (ECU) }\end{array}$ & $\begin{array}{c}\text { Efficiency } \\
(\%)\end{array}$ & $\begin{array}{l}\text { Avg. } \\
\text { (ECU) }\end{array}$ & $\begin{array}{c}\text { 1-Shot } \\
(\%)\end{array}$ & $\begin{array}{c}\text { Machine } \\
(\%)\end{array}$ \\
\hline \multicolumn{9}{|l|}{ Substitutes } \\
\hline Strong & $1-6$ & 48 & 14.63 & 34.8 & 17.6 & 0.3 & 9.6 & \\
\hline Unilateral & $1-6$ & 48 & 15.05 & 34.6 & 16.5 & 0.2 & 6.5 & 3.7 \\
\hline Bilateral & $1-6$ & 48 & 14.76 & 34.7 & 16.9 & 0.3 & 10.5 & 0.2 \\
\hline Hot & $1,3,4,5$ & 32 & 15.27 & 34.7 & 16.9 & & & \\
\hline \multicolumn{9}{|l|}{ Complements } \\
\hline Strong & $1-6$ & 48 & 15.03 & 34.1 & 10.9 & 0.2 & 5.1 & \\
\hline Unilateral & $1-6$ & 48 & 12.61 & 35.3 & 23.2 & 0.2 & 5.1 & 3.0 \\
\hline Bilateral & $1-6$ & 48 & 13.11 & 34.0 & 10.1 & 0.2 & 6.8 & 0.4 \\
\hline Hot & $1,3,4,5$ & 32 & 14.44 & 35.6 & 26.2 & & & \\
\hline
\end{tabular}

Table 3: Summary of treatments. Stage game average payoffs and efficiency measures are across all matches and all stages.

be biggest when players are strongly committed.

Conjecture B-2 (Fear of miscoordination) There should be weakly less collusion with strategic complements than with strategic substitutes when players are strongly committed.

Finally, on the basis of previous experimental work by Potters and Suetens (2009), we could justify a conjecture that more collusion is to be expected with strategic complements than with strategic substitutes when players are not committed at all.

\section{Results}

Table 3 provides a summary of the eight treatments. In general participants had difficulty establishing more cooperative behavior, with stage game payoffs closer to the one-shot Nash payoff (33 ECU) than to the joint profit maximizing payoff (43 ECU). The treatments with strategic complements provided both the least and the most cooperative behavior, with low levels of cooperation in the strong and bilateral treatments and high levels in the unilateral and hot treatments. In all treatments, participants incurred very low costs for deviating from or modifying their machines. One-shot deviations are observed in less than $11 \%$ of stage games. In the unilateral treatments, machine modifications were minimal (after less than $4 \%$ of stage games), while in the bilateral treatment, in which mutual agreement was required, such changes were rare (after less than $1 \%$ of stage games).

The majority of the subsequent analysis uses data from the last third of a session (matches 7-10). This sub-sample provides a reasonable trade-off between using the final matches, where subject behavior is most likely to have converged, and ensuring enough observations. Analysis explicitly on the evolution of behavior across matches, as well as some analysis that focuses 


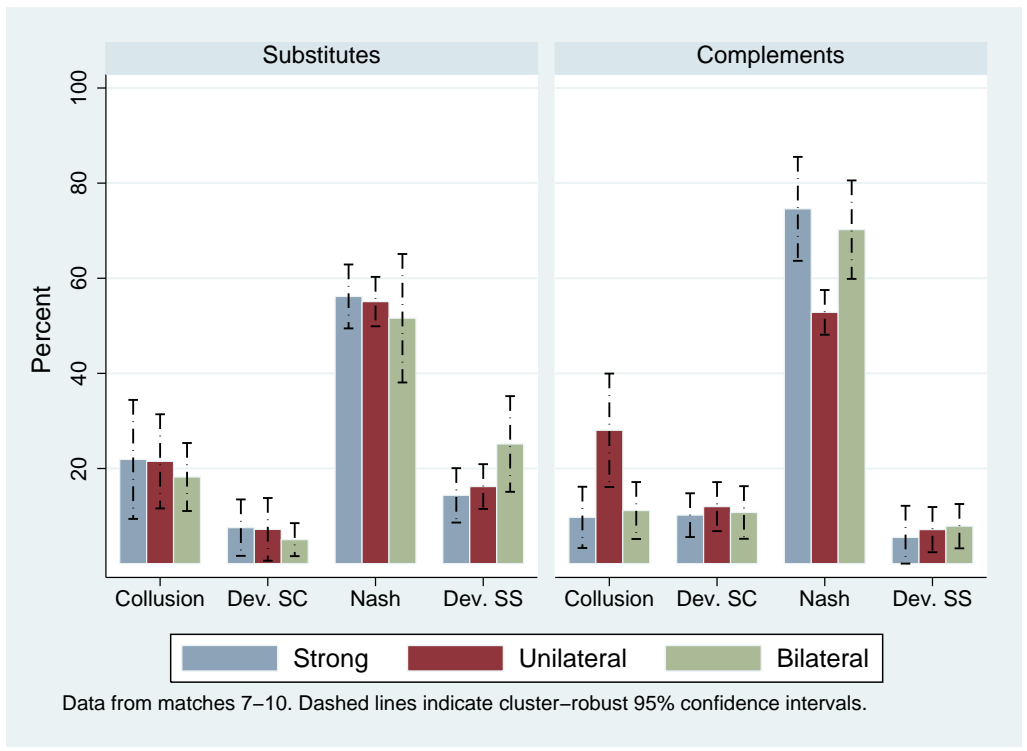

Figure 1: Average stage-game action choices.

on very particular histories for which there is the need to expand the sample size, uses data from the last two-thirds of a session (matches 4-10).

The results are presented in three subsections dealing with the impact of strategic commitment on cooperation, the difference between strategic complements and substitutes and the strategies participants use. All reported regressions and statistical tests use cluster-robust standard errors, corrected for arbitrary correlation at the matching-group level.

\subsection{Impact of strategic commitment on cooperation}

Figure 1 provides an overview of the impact of strategic commitment on action choices in the stage games. The left-hand panel shows that, with strategic substitutes, commitment has a minimal impact on choices, with the exception of a small increase in the rate of $\mathrm{D}$ choices (Dev.SS) in the bilateral commitment variation. The situation is markedly different with strategic complements, as is shown in the right-hand panel. Here, the strong and bilateral commitment variations display much higher rates of Nash choices compared to the unilateral variation. Collusion mirrors this pattern, with the former treatments being associated with less collusion, while the latter is associated with more. For B and D choices (Dev.SC and Dev.SS) there is little variation across the levels of commitment.

Figure 2 shows the evolution of collusion over time. The top panel shows this time trend across matches. With strategic substitutes (left panel), collusion is increasing over matches for the strong and unilateral commitment variations, while no clear trend is seen when bilateral consent is needed to modify machines. An obvious ranking of commitment levels, on the extent to which it generates collusion, cannot be made on the basis of this graph. With strategic complements (right panel), the graph illustrates a clear separation of commitment 


\begin{tabular}{|c|c|c|c|c|}
\hline & \multicolumn{2}{|c|}{ Substitutes } & \multicolumn{2}{|c|}{ Complements } \\
\hline & (1) & $(2)$ & (1) & $(2)$ \\
\hline Unilateral & $-0.07 \quad(0.873)$ & $0.24 \quad(0.670)$ & $1.05^{* *}(0.037)$ & $-0.28 \quad(0.670)$ \\
\hline Bilateral & $-0.05 \quad(0.879)$ & $0.99^{* *} \quad(0.038)$ & $-0.76 \quad(0.241)$ & -1.91 \\
\hline Stage & $-0.09^{* * *}(0.000)$ & $-0.08^{* * *}(0.000)$ & $(0.087)$ & $-0.15^{*}$ \\
\hline Unilateral x Stage & $0.02 \quad(0.648)$ & $0.01 \quad(0.718)$ & $(0.557)$ & $(0.470)$ \\
\hline Bilateral x Stage & $(0.233)$ & $-0.04^{*} \quad(0.070)$ & $(0.115)$ & $(0.109)$ \\
\hline Match & & $0.35^{* * *}(0.000)$ & & $-0.10 \quad(0.361)$ \\
\hline Unilateral x Match & & $-0.12 \quad(0.435)$ & & $0.52^{* * *}(0.000)$ \\
\hline Bilateral x Match & & $-0.40^{* *} \quad(0.021)$ & & $0.44^{*} \quad(0.093)$ \\
\hline Constant & $-0.60^{* * *}(0.002)$ & $-1.45^{* * *}(0.000)$ & $-2.25^{* * *}(0.000)$ & $-1.92^{* * *}(0.003)$ \\
\hline Included Matches & $7-10$ & $7-10$ & $7-10$ & $7-10$ \\
\hline Included Stages & $1-12$ & $1-12$ & $1-12$ & $1-12$ \\
\hline M-S Dummies & Yes & Yes & Yes & Yes \\
\hline Cluster VCE & Yes & Yes & Yes & Yes \\
\hline
\end{tabular}

Table 4: Logit regression of the probability of choosing the collusive action. The baseline case is the strong commitment treatment. ${ }^{* * *} 1 \%,{ }^{* *} 5 \%,{ }^{*} 10 \%$ significance.

levels. Collusion rates are highest under unilateral. With strong and bilateral commitment, collusion rates are lower. There is a trend for collusion rates to increase over time in the unilateral treatment. However, no such trend is evident for the other commitment types. ${ }^{13}$ The bottom panel of Figure 2 shows how the rates of collusion change within a match. It displays the typical pattern of collusion decreasing sharply after the first few periods, then remaining approximately constant at a lower level.

A logistic regression of the probability of choosing the collusion action is used to formally quantify the effect of strategic commitment. Table 4 reports the results of this analysis separately for strategic complements and substitutes. In the first column, a complete set of commitment-type dummies is interacted with the stage number of the match. ${ }^{14}$ This regression confirms the overall message of Figure 1, namely that strategic commitment has no impact on rates of collusion under strategic substitutes, but has a significant impact under strategic complements. With strategic complements, the unilateral variation is associated with significantly higher rates of collusion, while the strong and bilateral variation have statistically similar rates.

The second column, expands the specification to include the match number as a dependent variable. Doing so reveals the effects of strategic commitment to work primarily through

\footnotetext{
${ }^{13}$ These patterns are most easily seen in Figure 9 of Appendix D, which graphs the predicted rates of collusion.

${ }^{14}$ Only data from stages twelve or earlier is used. This restriction is used since later stages did not exist in each match for each matching group (see Table 2). The regression includes matching-group dummies that control for possible fixed effects resulting from the particular combination of stages and matches drawn. See Appendix D for a series of robustness checks for these regressions, including checks for the inclusion of matching-group dummies (Table 13), the data sub-sample used (Table 14) and the parametric form of the model (Table 15).
} 

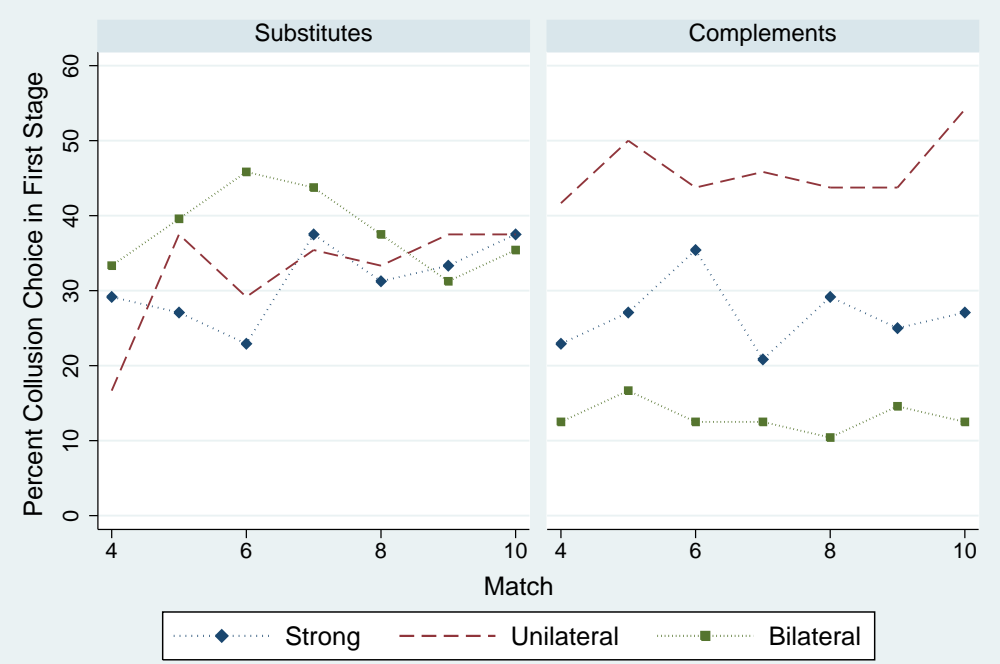

Data from matches $4-10$ and stages $1-12$.

(a) Collusion choice across matches.

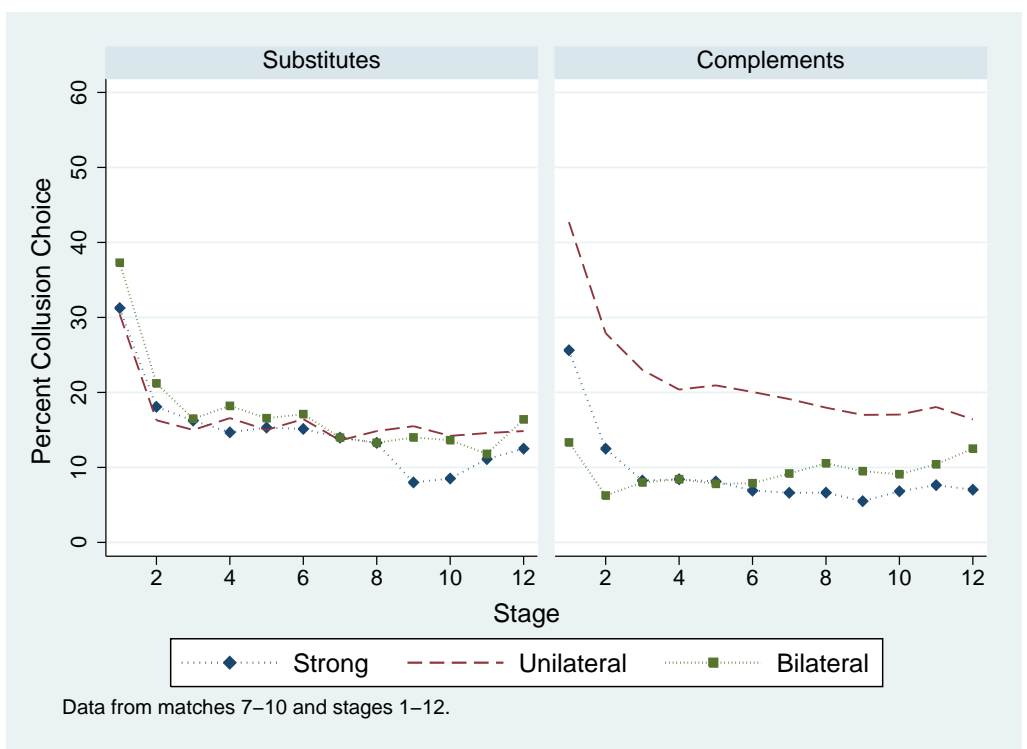

(b) Collusion choice within matches.

Figure 2: The effect of strategic commitment on collusion with strategic substitutes and complements: percentage of collusion. 


\begin{tabular}{|c|c|c|c|c|}
\hline & \multicolumn{2}{|c|}{ Substitutes } & \multicolumn{2}{|c|}{ Complements } \\
\hline & (1) & (2) & (1) & (2) \\
\hline Unilateral & $-0.06 \quad(0.444)$ & $-0.02 \quad(0.817)$ & $0.19^{* * *}(0.000)$ & $0.04 \quad(0.436)$ \\
\hline Bilateral & $-0.05 \quad(0.573)$ & $0.00 \quad(0.988)$ & $-0.04 \quad(0.428)$ & $-0.13 \quad(0.116)$ \\
\hline Stage & $-0.02^{* * *}(0.000)$ & $-0.02^{* * *}(0.000)$ & $-0.01^{* *}(0.037)$ & $-0.01^{* *}(0.043)$ \\
\hline Unilateral x Stage & $0.01 \quad(0.147)$ & $0.01 \quad(0.180)$ & $-0.01 \quad(0.265)$ & $-0.01 \quad(0.407)$ \\
\hline Bilateral x Stage & $(0.955)$ & $-0.00 \quad(0.965)$ & $(0.341)$ & $(0.266)$ \\
\hline Match & & $0.05^{* * *}(0.000)$ & & $0.01 \quad(0.509)$ \\
\hline Unilateral x Match & & $-0.01 \quad(0.672)$ & & $0.06^{* * *}(0.004)$ \\
\hline Bilateral x Match & & $-0.02 \quad(0.257)$ & & $0.03 \quad(0.136)$ \\
\hline Constant & $0.38^{* * *}(0.000)$ & $0.27^{* * *}(0.000)$ & $0.12^{* * *}(0.003)$ & $0.11^{* * *}(0.007)$ \\
\hline Included Matches & $7-10$ & $7-10$ & $7-10$ & $7-10$ \\
\hline Included Stages & $1-12$ & $1-12$ & $1-12$ & $1-12$ \\
\hline M-S Dummies & Yes & Yes & Yes & Yes \\
\hline Cluster VCE & Yes & Yes & Yes & Yes \\
\hline
\end{tabular}

Table 5: Linear random-effects regression of payoff efficiency in the stage game. The baseline case is the strong commitment treatment. ${ }^{* *} 1 \%,{ }^{* *} 5 \%,{ }^{*} 10 \%$ significance.

dynamics across matches, as opposed to dynamics within matches or even simple shifts. These regressions show significant effects for the bilateral variation in the treatments with strategic complements and substitutes, although via different channels. ${ }^{15}$

A second measure of the cooperative nature of subjects' behavior is the implied efficiency of their choices: the actual surplus generated over and above the one-shot Nash equilibrium as a percentage of the maximum available surplus. Contrary to focussing on the probability of choosing the collusive action, this measure aggregates the impact of all choices, including partial collusion and deviation choices. Figure 3 shows the evolution of efficiency both across matches (top panel) and within matches (bottom panel). Table 5 provides an analogous analysis to Table 4 for efficiency. ${ }^{16}$ As can be seen, the dynamics of realized efficiency levels, both across matches and within matches, mimics many of the features of the collusion choice. In particular, across matches, there is again the clear separation of the strong and bilateral variation from the unilateral variation with strategic complements, while with strategic substitutes all commitment types end up with similar rates of efficiency by the start of match 10. Within matches, all treatments show the same pattern of decline of efficiency as a match continues.

The following result summarizes our findings with respect to the impact of strategic commitment on collusion.

Result 1 (i) With strategic substitutes, there is no effect of strategic commitment on average collusion. (ii) With strategic complements, strategic commitment has a negative effect on

\footnotetext{
${ }^{15}$ Again, these features can be seen clearly in Figure 9 of Appendix D, which visualizes the predicted rates of collusion.

${ }^{16}$ Figure 10 in Appendix D illustrates the fitted behavior.
} 


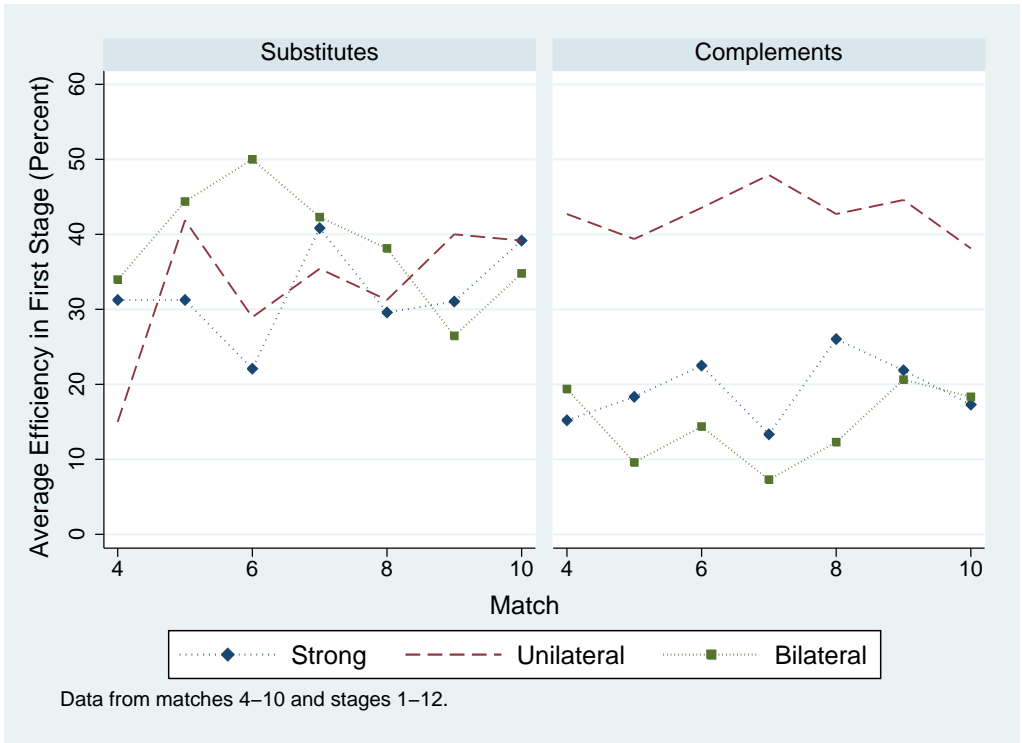

(a) Efficiency across matches.

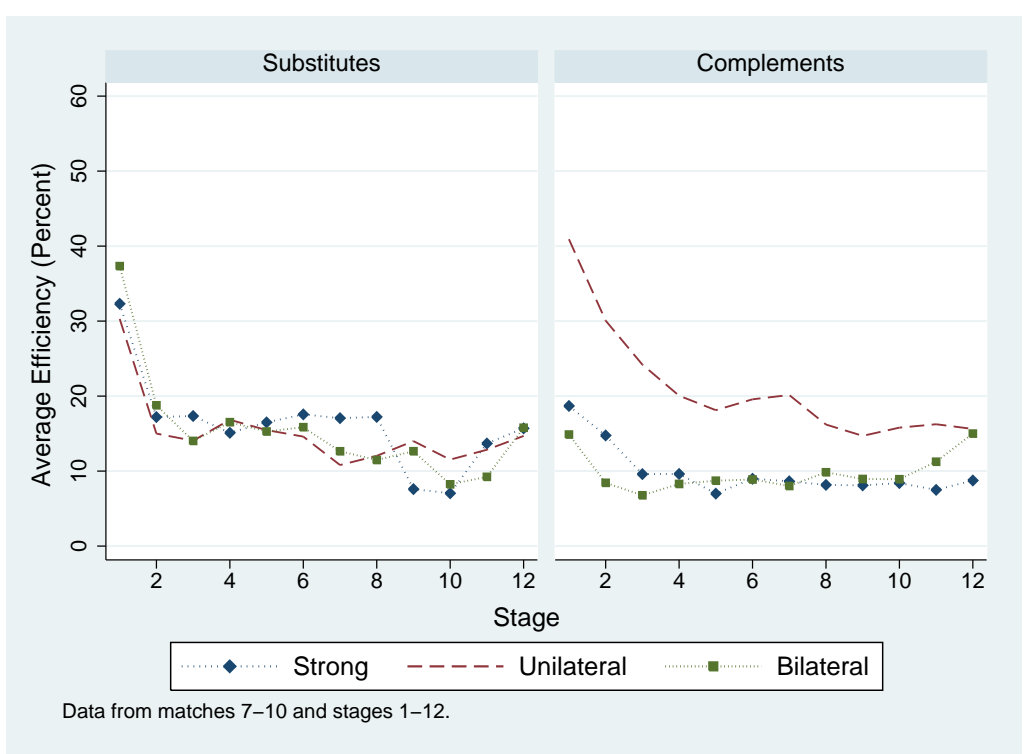

(b) Efficiency within matches.

Figure 3: The effect of strategic commitment on efficiency with strategic complements and substitutes. 
collusion.

With strategic substitutes, the effect is consistent with Conjecture A-0 that is formulated on basis of standard game theoretical prediction. The evidence is also consistent with the renegotiation literature, though, since collusion can be sustained in a weak renegotiation proof equilibrium.

With strategic complements, a different picture emerges. Here, strategic commitment does have an effect on observed levels of collusion and the direction of this effect is in the opposite direction to that predicted by renegotiation theory. Strategic commitment is detrimental to collusion under strategic complements. This effect is consistent with Conjecture A-2 that is based on the notion of fear of miscoordination.

\subsection{Difference between complements and substitutes}

While the previous subsection concentrated on the effect of manipulating the level of strategic commitment, it is clear that there is an interaction effect associated with the type of strategic interaction. With greater strategic commitment - that is, under the strong or bilateral variation - there is more collusion with strategic substitutes than with strategic complements. However, without this strategic commitment - that is, under the unilateral variation - there is more collusion with strategic substitutes. ${ }^{17}$

This strategic interaction effect is quantified using analogous regression specifications to those reported in Table 4, except the data from both game types are pooled and additional dependent variables are added - a strategic complements indicator interacted with the level of commitment and stage and the level of commitment and match. Table 6 reports the results of this exercise for the variables with an interaction with the strategic complements indicator variable. These results confirm the overall message, with respect to the comparison across game types, given in Figure 2. Namely, there is a significant effect of the type of strategic interaction on the development of collusion across matches. Except for the bilateral variation, which is significantly different, the development of collusion within a match is comparable across game types.

Result 2 There is more collusion with strategic complements when the level of strategic commitment is low and more collusion with strategic substitutes when the level of commitment is high.

This results is inconsistent with Conjectures B-0 and B-1 as the type of strategic interaction does affect the level of collusion we observe (for all levels of commitment). Result 2 is consistent with Conjecture B-2, for high level of commitment, and with previous experimental

\footnotetext{
${ }^{17}$ Figure 1 indicates some more direct strategic interaction effects with respect to action choices other than collusion (A) or Nash (C). In particular, Dev.SS (C) is more frequent under strategic substitutes than under strategic complements, while the opposite is (marginally) true for Dev.SC (B). However, these are to be expected given that the (one-shot) best response to the collusion action is Dev.SS in the strategic substitutes game and Dev.SC in the strategic complements game.
} 


\begin{tabular}{|c|c|c|c|c|}
\hline \multirow[b]{3}{*}{ Complements } & \multicolumn{4}{|c|}{ Combined regression } \\
\hline & \multicolumn{2}{|c|}{ (1) } & \multicolumn{2}{|c|}{$(2)$} \\
\hline & -0.66 & $(0.186)$ & 0.49 & $(0.508)$ \\
\hline Complements x Unilateral & $1.08^{*}$ & $(0.087)$ & -0.52 & $(0.568)$ \\
\hline Complements x Bilateral & -0.70 & $(0.320)$ & $-2.86^{* *}$ & $(0.024)$ \\
\hline Complements x Stage & -0.06 & $(0.484)$ & -0.08 & $(0.405)$ \\
\hline Complements x Unilateral x Stage & 0.04 & $(0.681)$ & 0.06 & $(0.563)$ \\
\hline Complements x Bilateral x Stage & $0.18^{*}$ & $(0.064)$ & $0.21^{* *}$ & $(0.047)$ \\
\hline Complements x Match & & & $-0.45^{* * *}$ & $*(0.008)$ \\
\hline Complements x Unilateral x Match & & & $0.62^{* * *}$ & $*(0.007)$ \\
\hline Complements x Bilateral x Match & & & $0.83^{* * *}$ & $*(0.004)$ \\
\hline Included Matches & \multicolumn{2}{|c|}{$7-10$} & \multicolumn{2}{|c|}{$7-10$} \\
\hline Included Stages & \multicolumn{2}{|c|}{$1-12$} & \multicolumn{2}{|c|}{$1-12$} \\
\hline Stage Var. & \multicolumn{2}{|c|}{ Yes } & \multicolumn{2}{|c|}{ Yes } \\
\hline Match Var. & \multicolumn{2}{|c|}{ No } & \multicolumn{2}{|c|}{ Yes } \\
\hline M-S Dummies & \multicolumn{2}{|c|}{ Yes } & \multicolumn{2}{|c|}{ Yes } \\
\hline Cluster VCE & \multicolumn{2}{|c|}{ Yes } & \multicolumn{2}{|c|}{ Yes } \\
\hline
\end{tabular}

Table 6: Logit regression of the probability of choosing the collusive action - strategic complements versus substitutes. The baseline case is the strong commitment treatment with strategic substitutes. ${ }^{* * *} 1 \%,{ }^{* *} 5 \%,{ }^{*} 10 \%$ significance.

findings by Potters and Suetens (2009), for low levels of commitment. However, this results adds important new insights to theirs: the differential impact of the type of strategic interaction on collusion strongly depends on the level of commitment. When there is a low level of commitment, more collusion is observed with strategic substitutes than with complements, whereas the situation reverses when there is a high level of commitment.

\subsection{Individual behavior}

The previous subsections dealt with the impact of strategic commitment and type of strategic interaction by assessing outcomes along the realized path of play. To understand further what drives these realized paths, this subsection analyses individuals' intended strategies and their deviations from these strategies.

\subsubsection{Initial choices}

Figure 4 shows the average initial choices of the participants in the matches 7 through 10 . Compared to the average action choice across all stages (see Figure 1), the rate of collusion choice is higher and that of Nash choices lower, for all commitment variations except bilateral. This difference in collusion choice does not come as a surprise, given the, generally, positive match effect and the negative stage effect in the regressions of Table 4.

With strategic substitutes the figure does not show any impact of commitment level on initial choices. In contrast, with strategic complements, strategic commitment matters. Compared to the unilateral variation, there is a higher rate of Nash choices and a lower rate of 


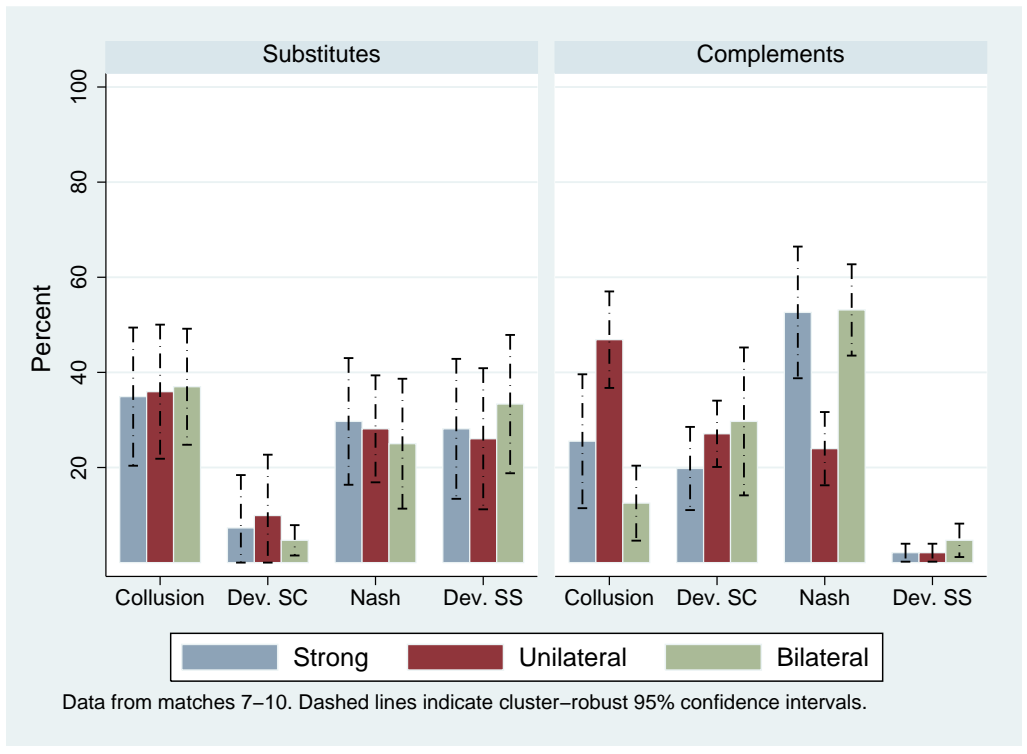

Figure 4: Average initial choices.

collusive choices for the strong and bilateral variation. For the other actions - Dev.SC and Dev.SS - there is no notable difference between commitment variations.

In sum, all key treatment differences and similarities that were found for average action choices across all stages are already present in the initial choices. This raises the question whether the differences and similarities in choices across all stages are completely induced by the initial choices. Appendix $\mathrm{C}$ presents results of simulations that aim to control for path dependencies. In these simulations, for each treatment, transition matrices are derived from the intended (machine) and actual choices. To control for the impact initial choices may have on the realized path, the paths of the resulting processes are studied starting from equal initial states. The outcomes provide evidence that the treatment differences and similarities in choices across all stages are not purely induced by initial choices.

\subsubsection{Dynamic responses (machines)}

Table 7 gives the distribution of machines that participants programmed at the beginning of matches 7-10. The seven types of machines that are reported in the table are the only ones that were used with a frequency of at least 5 percent in at least one of the treatments. All the reported machines seem reasonable, with the majority corresponding to strategies that are commonly seen either in prior experimental studies or from the theory of repeated games. The first four (AAAA, ABC(C/D), ACCC and BBCC) attempt to establish some collusion - either unconditionally or conditionally - and are used 26-35 percent of the time in all treatments. The non-cooperative Nash machine (CCCC) is used 10-26 percent of the time. The myopic best response is used 12-25 percent of the time (with substitutes this is the DCCC-machine; with complements the BCCC-machine). As expected, the DCCC-machine was rarely used 


\begin{tabular}{|c|c|c|c|c|c|c|c|}
\hline & \multirow[b]{2}{*}{ Machine } & \multicolumn{3}{|c|}{ Substitutes } & \multicolumn{3}{|c|}{ Complements } \\
\hline & & Strong & Unilateral & Bilateral & Strong & Unilateral & Bilateral \\
\hline Uncond. coop. & $\overline{\mathrm{AAAA}}$ & 0.01 & 0.05 & 0.01 & 0.01 & 0.08 & 0.01 \\
\hline Cond. coop. & $\mathrm{ABC}(\mathrm{C} / \mathrm{D})$ & 0.18 & 0.11 & 0.16 & 0.10 & 0.23 & 0.18 \\
\hline Nash reversion & $\mathrm{ACCC}$ & 0.13 & 0.07 & 0.16 & 0.16 & 0.13 & 0.05 \\
\hline Part. coll + Nash rev. & $\mathrm{BBCC}$ & 0.01 & 0.02 & 0.02 & 0.05 & 0.01 & 0.07 \\
\hline Nash & $\mathrm{CCCC}$ & 0.17 & 0.22 & 0.10 & 0.22 & 0.14 & 0.26 \\
\hline \multirow[t]{2}{*}{ Myopic best reponse } & DCCC & 0.16 & 0.19 & 0.12 & & & \\
\hline & $\mathrm{BCCC}$ & & & & 0.25 & 0.15 & 0.21 \\
\hline Punishing & DDDD & 0.00 & 0.03 & 0.07 & 0.00 & 0.00 & 0.00 \\
\hline Other & 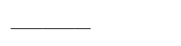 & 0.35 & 0.31 & 0.36 & 0.20 & 0.27 & 0.22 \\
\hline
\end{tabular}

Table 7: Machine categorization: Distribution of machines in initial stages of matches 7-10 across treatments. Machines that are used with frequency below 5 percent in every treatment are categorized as "Other".

with complements; possibly less expected, though, is the rare use of the BCCC-machine with substitutes. The punishing machine (DDDD) was used once at a frequency above 5 percent, and this was in a treatment where machine modifications were the easiest to implement. ${ }^{18}$

Result 3 Irrespective of the type of strategic interaction and the level of strategic commitment, the four most prominent machines are tit-for-tat (ABCD), Nash reversion (ACCC), Nash (CCCC) and myopic best response (DCCC or BCCC). All other machines are used less than 10 percent of the time in every treatment.

Table 7 suggests that, with a high level of strategic commitment (i.e. in the strong or bilateral variations), the difference in the type of machine used, when comparing strategic substitutes to complements, is mainly in the use of the myopic best response machine. With strategic substitutes, the myopic best response (DCCC) is used 16/12 percent of the time (strong/bilateral), whereas the comparable machine (BCCC) is used in 25/21 percent of the time (strong/bilateral) with strategic complements. Cooperative machines account for 3335 percent and 31-33 percent of the machines with strategic substitutes and complements, respectively.

For low levels of strategic commitment (unilateral), the situation changes. Here, the use of the myopic best response is not so different across the two interaction types - 19 percent with strategic substitutes and 15 percent with complements. The most prominent difference is instead the use of cooperative machines. With strategic complements 45 percent of machines are cooperative, while only in 26 percent of instances do participants start out with a cooperative machine in strategic substitutes. Consequently, strategic complementarity

\footnotetext{
${ }^{18} 18-34$ percent of the machines are categorized as "Other". This group comprises machines that all are used less than 5 percent of the time in every treatment. Table 16 in Appendix D decomposes this category further, and shows that these seven prominent machines give a fair characterization in the sense that many machines categorized as "Other" are minor deviations from these prominent seven.
} 


\begin{tabular}{|c|c|c|c|c|c|c|}
\hline \multirow[b]{2}{*}{ Matches } & \multicolumn{3}{|c|}{ Substitutes } & \multicolumn{3}{|c|}{ Complements } \\
\hline & Strong & Unilateral & Bilateral & Strong & Unilateral & Bilateral \\
\hline $1-3$ & 0.114 & 0.082 & 0.103 & 0.047 & 0.077 & 0.049 \\
\hline $4-6$ & 0.075 & 0.077 & 0.115 & 0.043 & 0.054 & 0.084 \\
\hline $7-10$ & 0.100 & 0.051 & 0.099 & 0.058 & 0.037 & 0.067 \\
\hline
\end{tabular}

Table 8: Frequency of one-shot deviations in the different treatments in different matchclusters.

appears to induce more collusive behavior when opponents are not strongly committed to their initial intended strategies.

In addition, keeping the type of strategic interaction constant, there are strong differences in the machines used for the various commitment levels. With strategic substitutes, initial machines in the bilateral variation are programmed to punish the use of the deviation action more harshly than for the strong $(p=0.0053)$ or unilateral $(p=0.0128)$ variations. With strategic complements, there are even more differences. Machines respond more collusively to actions $\mathrm{A}(p<0.0001)$ and $\mathrm{B}(p=0.0005)$ for the low level of commitment (unilateral) than for the high level of commitment (strong). The responses to action A are also significantly different for the bilateral variation compared to the strong $(p=0.0142)$ and unilateral $(p<$ $0.0001)$ variations.

Result 4 Participants tend to hold more cooperative machines with strategic substitutes if the level of strategic commitment is high. With strategic complements they tend to hold more cooperative machines if the level of strategic commitment is low.

We complete the machine analysis by investigating when and how participants implement one-shot deviations and machine modifications.

One-shot deviations Table 8 shows the frequency of one-shot deviations across the different treatments. It can be seen that one-shot deviations are rarely used (on average, less than 10 percent of all instances). In the final matches, one-shot deviations are less frequent in the unilateral variation, and throughout all matches less frequent with strategic complements than with strategic substitutes for all commitment levels. However, these treatment differences are by and large not significant. ${ }^{19}$

We also ask whether the frequency of one-shot deviations depends on the machine that the individual holds at the time of the one-shot deviation. The machine AAAA (unconditional

\footnotetext{
${ }^{19}$ Established using logit regressions on the probability of a one-shot deviation in the first twelve stages of a match using data from all matches and just matches 7-10. Treatment and stage dummies, plus their interaction terms, were included as independent variables; standard errors were clustered by matching group. In addition, a regression was run in which all commitment levels were grouped, and used to test for differences between strategic substitutes and complements. The only significant effect was for the bilateral variation with strategic complements, where one-shot deviations were initially less frequent but tended to increase more over time. Regression tables are available upon request.
} 
cooperation) triggers one-shot deviations in 45-77 percent of the instances for the strong and bilateral commitment variations. However, these deviations came from very few participants and hence should be interpreted with care. All other machines are much less likely to involve one-shot deviations, with frequencies below 10 percent in all treatments. Table 17 in Appendix D summarizes these results.

One-shot deviations from the unconditional cooperative machine (AAAA) are used exclusively to play Nash or to punish, where the punishment action coincides with the myopic best response in the case of strategic substitutes. Deviations from the Nash machines (CCCC) are mostly used to establish full or partial collusion. See Table 18 in Appendix D for further details.

Unilateral modifications Figure 5 illustrates the effect of unilateral machine modifications on average machines. Two points should be noted. First, average machines are "steeper" and more cooperative - that is, respond more often with a collusive action if the opponent has chosen the collusive action in the previous stage - with strategic complements. Indeed, the difference in average machines is there in all commitment variations and highly significant according to a two-sided Mann-Whitney test (strong: $p=0.0006$; unilateral: $p<0.0001$; bilateral: $p=0.0001) \cdot{ }^{20}$

Second, unilateral deviations tend to make machines more cooperative with strategic substitutes and less cooperative with strategic complements. This effect is significant (according to a two-sided Mann-Whitney test) for responses to actions A and B with strategic substitutes in matches $4-10$ ( $p=0.0132$ and $p=0.0426$ respectively). With strategic complements the effect is significant for responses to action A in matches $7-10(p<0.0001)$ and to actions B, $\mathrm{C}$ and $\mathrm{D}$ in matches $4-10(p=0.0126, p=0.0951$ and $p=0.0982$ respectively $) .{ }^{21}$

Bilateral modifications During matches 7-10 there were only 6 bilateral deviations with strategic substitutes and 9 with strategic complements from respectively 5 and 7 machines. Given this small number of observations, it is not possible to produce sensible graphs equivalent to those in Figure 5. Despite these low numbers of actual modifications, many more attempts to modify are undertaken: 92 with strategic substitutes and 128 with strategic complements. $^{22}$

\footnotetext{
${ }^{20}$ These tests are based on 192 observations per treatment and hence are likely to underestimate standard deviations somewhat, since each participant appears four times in the sample (once for each match 7-10).

${ }^{21}$ Table 19 of Appendix D reports participants' propensity to modify their machine conditional on holding a particular machine.

${ }^{22}$ Table 20 of Appendix D reports participants' eagerness to modify their machine conditional on holding a particular machine.
} 


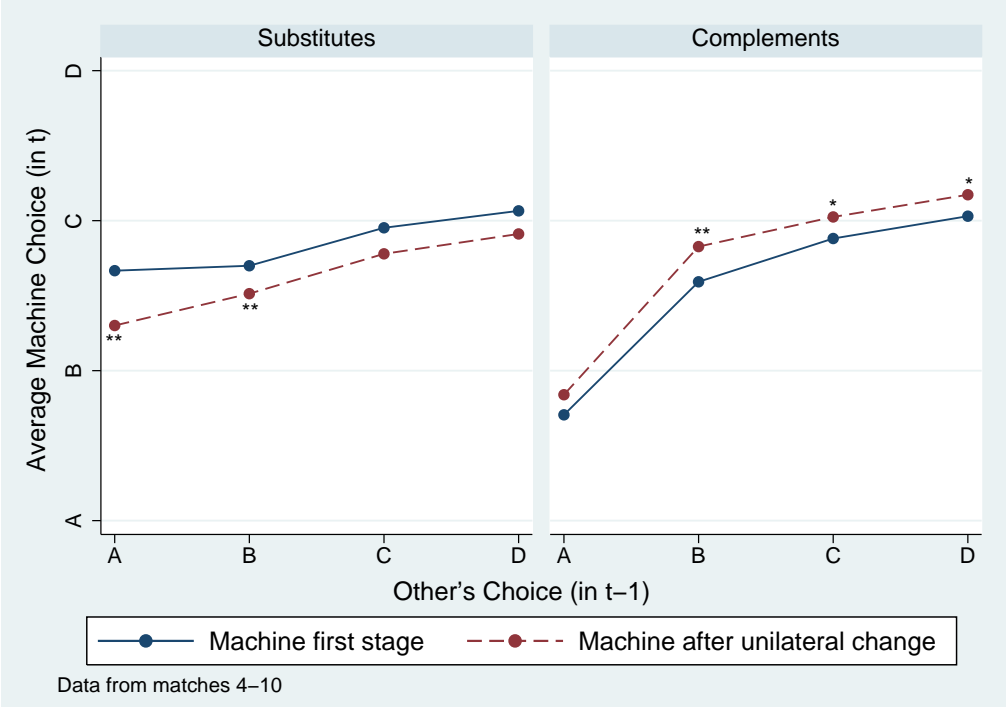

(a) Matches 4-10.

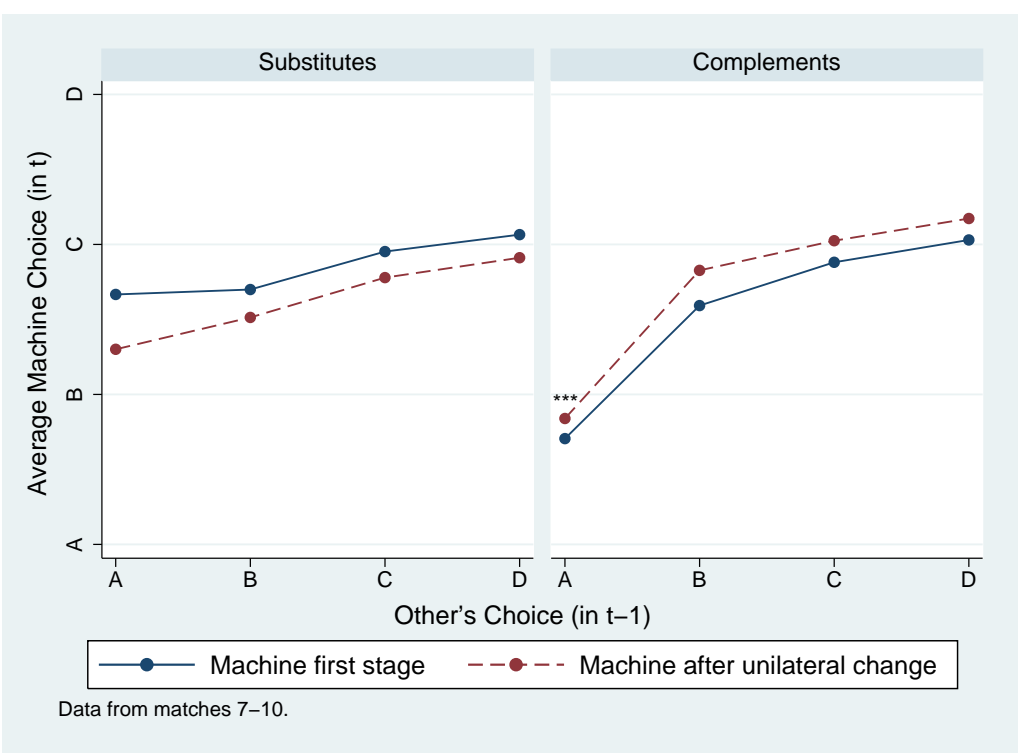

(b) Matches $7-10$.

Figure 5: The effect of unilateral deviations on average machines. Stars indicate significance levels according to a two-sided Mann-Whitney test. ${ }^{* * *} 1 \%,{ }^{* *} 5 \%,{ }^{*} 10 \%$ significance. 


\section{Discussion}

For the purposes of providing a benchmark, our results show similarities and differences with prior experimental studies on cooperation in repeated games. Comparing our results to studies using indefinitely repeated prisoners' dilemma stage games, we find, as elsewhere, that cooperation being part of a subgame Nash equilibrium is not a sufficient condition to observe high rates of cooperation. Indeed, compared to the prisoners' dilemma game, our four action games of strategic complements and substitutes display relatively low overall rates of cooperation. For example, cooperation is much more prevalent in the most comparable treatment from Dal Bó and Fréchette (2011a), where observed rates of the order of $60 \%$ averaged over all rounds in all matches. ${ }^{23}$ However, the dynamic responses that we observed do correspond to strategies that are commonly seen in other experiments; in particular, titfor-tat, always Nash and Nash reversion.

Our results show that, while strategic commitment has no effect on collusion under strategic substitutes, it has a significantly negative effect under strategic complements. The effect is such that there is more collusion under strategic complements when commitment is low (as is also found in Potters and Suetens, 2009), whereas there is more collusion under strategic substitutes when commitment is high. There are two commonly used equilibrium selection concepts that give some role for strategic commitment, namely renegotiation-proofness and risk-dominance. We consider each notion in turn and find that neither concept can provide an explanation for our observed treatment effects. We suggest an alternative that is based on fear of miscoordination, which can capture all our treatment effects.

\subsection{Renegotiation}

The observed ranking of collusion rates across treatments goes against the intuition delivered by the renegotiation literature. In particular, with higher levels of strategic commitment, and hence reduced concerns for renegotiation, we observe less collusion under strategic complements. Although renegotiation should never happen in equilibrium - whether collusion is weak renegotiation proof or not - it is reasonable to expect the strategic forces that drive the concept would need to be learnt by experience. Consequently, there is still the possibility that subjects engaged in something like renegotiation, but that such efforts did not feed back into reduced collusion at the beginning of a match.

As shown in the results, bilateral modifications take place very rarely. Consequently, there are few instances where participants succeeded in coordinating on a mutual modification of their machines. Still, the data collected on strategic decisions throughout the experiment

\footnotetext{
${ }^{23}$ The most comparable treatment of theirs has a cooperation payoff of 40 and a discount factor of $3 / 4$. Compared to our games, their (normalized) temptation (and sucker) payoffs are a little lower, which would suggest lower cooperation rates in our implementation. However, our discount rate of $7 / 8$ is larger, which would suggest to find higher rates of cooperation in our set-up. In both cases, cooperation is risk dominant, as defined in their paper.
} 
allows some analysis regarding which paths are "renegotiated", and if so, how. Thereto, we study when and how machines are (attempted to be) modified conditional on the last outcome of the realized path of play. We classify paths into three categories: (i) "failed collusion" (outcomes (B,A) and (A,B)), (ii) "miscoordination" (from the perspective of a cooperative agent; outcomes $(\mathrm{A}, \mathrm{C}),(\mathrm{A}, \mathrm{D}),(\mathrm{B}, \mathrm{C})$ and $(\mathrm{B}, \mathrm{D}))$ and (iii) "punishment paths" (outcomes $(\mathrm{C}, \mathrm{D}),(\mathrm{D}, \mathrm{C})$ and $(\mathrm{D}, \mathrm{D}))$. After a "miscoordination" stage, participants mostly try to modify cooperative machines into more punishing machines. Along "punishment paths", participants mostly (want to) modify non-cooperative machines, but rarely modify them into more collusive machines. ${ }^{24}$ Hence, there is no strong evidence that participants engaged in something like renegotiation.

\subsection{Risk-dominance}

Given the large number of possible equilibria in these indefinitely repeated games, it seems intuitive that considerations of renegotiation might be overshadowed by concerns of coordination on one of the different equilibria. Hence, it seems intuitive to look at risk-dominance, since it gives some role for a fear of equilibrium miscoordination. As discussed in Dal Bó and Fréchette (2011a), extending the idea of risk-dominance to infinitely repeated games posses a number of difficulties, even with only two actions for each player. These difficulties include extending the definition to repeated-game strategies and the issue that two repeated-game strategies can generate equivalent outcome paths. To these difficulties, our environment also adds the issue of extending the definition to more action choices in the stage game.

Blonski, Ockenfels, and Spagnolo (2011) consider an extension of the concept to the repeated prisoners' dilemma that involves only the strategies permanent Nash reversion and always Nash. Translating this approach to our environment results in the prediction that Nash reversion, with an initial choice of cooperation, is the risk-dominant strategy for both types of strategic interaction and all levels of strategic commitment. ${ }^{25}$ In what follows, we discuss how a definition of fear of miscoordination, which does not restrict itself to equilibrium miscoordination, can accommodate the observed behavior.

\footnotetext{
${ }^{24}$ See Table 21 in Appendix D for details.

${ }^{25}$ When focussing only on the Nash reversion and always Nash strategies, there is only one difference between the strategic complement and strategic substitute games: the $(\mathrm{A}, \mathrm{C})$ payoff in the complements game is lower than that in the substitutes game (14 rather than 25). With a discount rate of $7 / 8$ and the uniform prior as the belief of the opponent's strategy, this difference is too small to result in different predictions for the risk-dominance concept. One could consider allowing for a non-uniform prior. However, only a relatively small range of beliefs would result in the always Nash machine being selected in the complements game, whereas the Nash reversion machine is selected in the substitutes game. The weight on the opponent choosing the always Nash machine would need to be at least $77 \%$ and no more than $88 \%$. There is no support in the data for such a range of beliefs; see, for example, Table 7 .
} 


\subsection{Fear of miscoordination}

We have seen in Sections 3 and 4 that a notion of fear of miscoordination based on minmax regret is consistent with our treatment rankings both in terms of strategic commitment (Conjecture A-2) and type of strategic interaction (Conjecture B-2). In what follows, we consider whether there is any evidence in subject behavior for the mechanics of such fear of miscoordination. In terms of strategic commitment, participants do indeed use more cooperative machines in the unilateral variation for strategic complements $(52 \%)$ compared to the strong commitment variation (33\%, two-sided ranksum test $p<0.0001$; see also Table 22 in the Appendix). This is exactly as fear of miscoordination predicts (Conjecture A-2). Under substitutes, however, there is no such effect for strategic commitment. At this point, one could argue that this is simply a result of fear of miscoordination being weaker under substitutes. However, there is another crucial difference between substitutes and complements.

In the complements game the optimal deviation to the collusive action is "close" to the collusive action in the action space - such as a small price undercut in the Bertrand model while in the substitutes game the optimal deviation to the collusive action is "further away" from the collusive action in the action space - such as a supply beyond competitive levels in the Cournot model. ${ }^{26}$ In the experiment, around $90 \%$ of machines in the substitutes game respond to action $\mathrm{D}$ (Dev.SS) with either action $\mathrm{C}$ or $\mathrm{D}$, while in the complements game only about $60-80 \%$ respond to action B (Dev.SC) with action C or D (see Table 22 in Appendix D). Hence, the presence of defectors easily locks a population into paths involving only defection (actions $\mathrm{C}$ or D) in the substitutes game, whereas in the complements game a population may still remain in (partially) collusive outcomes (actions A or B). Thus, all else equal, one should expect less collusion in the substitutes game. Of course, the "all else equal" condition may not be satisfied, since participants may anticipate this and choose different strategies from the outset. In particular, if they understand these dynamics, it is reasonable to expect participants to refrain from choosing defective actions in the substitutes game, especially when there is strong strategic commitment.

Strong strategic commitment When participants are strongly committed to their strategy choices, they adopt the myopic best response strategy less often with strategic substitutes than with complements: only $16 \%$ of the machines have this characteristic in the former versus $25 \%$ in the latter (see Table 7 ). This difference is statistically significant ( $p=0.0321$; two-sided ranksum test on the myopic best response dummy with first stage machines in matches $7-10$ as the unit of independent observation). This difference is intuitive since, as argued above, it is easier to get stuck in a punishment cycle in the substitutes game when using such a machine. In the final three matches, we find that matches in which one of the participants used the myopic best response were stuck playing action $\mathrm{D}$ about $15 \%$ of the

\footnotetext{
${ }^{26}$ These differences are not detectable in $2 \times 2$ games, such as the prisoner's dilemma, and are a notable feature of our design.
} 
time with strategic substitutes and less than $1 \%$ of the time with complements. In fact, in the substitutes game, participants seem to have learned to avoid the dangerous myopic best response machine: it was more than twice as popular in the first three matches than in the final four matches ( $34 \%$ percent of the time in the first three matches). In the complements game, as opposed to the substitutes game, intentions can be masked while playing myopic best response, since the optimal deviation action coincides with partial collusion. Indeed, we do not see the previous trend in the use of myopic best responses in these treatments $(23 \%$ percent of the time in the first three matches).

While the myopic best response machine is more common with strategic complements if there is strong commitment, participants choose conditionally-cooperative machines somewhat more often with substitutes (40\% vs. 33\%; see Table 22). This is consistent with fear of miscoordination since, as we have seen in Subsection 3.3, the payoff consequences of miscoordinating with a cooperative machine tend to be more severe with strategic complements than with strategic substitutes (in terms of minmax regret).

Weak strategic commitment Under weak strategic commitment, masking intentions in the complements game is less effective than under strong strategic commitment. If participants truly miscoordinate on the collusive outcomes, with one player choosing action A while the other chooses action $\mathrm{B}$, then it is reasonable to expect the latter to implement a unilateral change towards full collusion. If this were not to happen, the intentions of the latter are no longer masked, and it becomes evident that they were myopically best responding rather than trying to cautiously implement collusion. Indeed, the myopic best response machine is used less under weak commitment (15\%) than under strong commitment (25\%). This difference is statistically significant ( $p=0.0156$; two-sided ranksum test on "myopic best response" dummy with first stage machines in matches 7-10 as the unit of independent observation). Now, in terms of the usage of the myopic best response machine, there is no longer a big difference between substitutes and complements: it is used $15 \%$ of the time in the complements game versus $19 \%$ of the time in the substitutes game.

Instead, under weak commitment, machines are more cooperative with complements than with substitutes. About $52 \%$ of the machines attempt to establish collusion (reply to action A with action A) in the complements game as opposed to only $35 \%$ in the substitutes game (see Table 22 in Appendix D). This difference is statistically significant ( $p=0.0010$; twosided ranksum test on dummy that indicates whether the machine is programmed to respond to action A with action A and with first stage machines in matches 7-10 as the unit of independent observation). The $52 \%$ of cooperative machines in the complements game with weak commitment also represent a significant increase compared to the earlier case with strong commitment ( $p=0.0003$; same test). It appears that myopic best responders, who could conceal their intentions under strong commitment, seem to be switching to more cooperative machines when such masking of intentions is no longer possible. As a consequence, there is 
more cooperation with complements than with substitutes under weak commitment.

\section{Conclusion}

We have studied the effect of strategic commitment on collusion in infinitely repeated games and found that, while strategic commitment does not affect collusion with strategic substitutes, it has a negative effect with strategic complements. The latter effect is strong enough that, although there is more collusion with substitutes if the level of strategic commitment is

high, there is more collusion with complements when the level of commitment is low.

We observe a great deal of heterogeneity in the strategies that participants use, but most participants use either one of the four following machines: Nash, myopic best response, titfor-tat or Nash reversion. The ratios with which these strategies are chosen differ across treatments. With strategic substitutes, participants learn to avoid the myopic best response strategy, in particular when they are strongly committed. In contrast, with strategic complements, participants avoid this machine only when they are weakly committed; with strong commitment, it is the most adopted strategy. We conjecture that, when participants are strongly committed, they can credibly mask their 'possibly hostile' intentions under strategic complements, where the optimal deviation action coincides with partial collusion. Starting with partial collusion can be justified for participants that in principle want to coordinate on full collusion, but are afraid of the consequences of miscoordinating when choosing the fully collusive outcome.

These results should be of interest to anyone interested in strategy elicitation in infinitely repeated games, anyone studying renegotiation or strategic commitment, and anyone interested in the factors (strategic interaction type, strategic commitment) that determine collusive behavior. Our results are also suggestive for the design of optimal antitrust regulation such as controlling the boundaries on strategic oversight within corporations. From the business perspective, our results indicate that the optimal level of strategic oversight within corporations depends on the underlying nature of their strategic interaction with rivals.

\section{References}

Abreu, D., D. Pearce, and E. Stachetti (1993): "Renegotiation and symmetry in repeated games," Journal of Economic Theory, 60(2), 217-240.

Andersson, O., And E. Wengström (2012): "Credible cooperation and communication: Experimental evidence from multi-stage games," Journal of Economic Behavior \& Organization, 81(1), 207-219.

Aramendia, M., C. Larrea, and L. Ruiz (2005): "Renegotiation in the repeated Cournot model," Games and Economic Behavior, 52(1), 1-19. 
Axelrod, D. (1984): The Evolution of Cooperation. Basic Books.

Bergemann, D., and K. Schlag (2008): "Pricing without priors," Journal of the European Economic Association, 6(2), 560-569.

Blonski, M., P. Ockenfels, and G. Spagnolo (2011): "Equilibrium selection in the repeated prisoner's dilemma: Axiomatic approach and experimental evidence," American Economic Journal: Microeconomics, 3(3), 164-192.

Brandts, J., And G. Charness (2000): "Hot vs. cold: Sequential responses and preference stability in experimental games," Experimental Economics, 2(3), 227-238.

Brosig, J., And C. YAng (2003): "Emotions and reasons in a hot vs. cold experiment," Experimental Economics, 6(1), 75-90.

Bulow, J., J. Geneakoplos, and P. Klemperer (1985): "Multimarket oligopoly: Strategic substitutes and complements," Journal of Political Economy, 93(3), 488-511.

Chassang, S. (2010): "Fear of miscoordination and the robustness of cooperation in dynamic global games with exit," Econometrica, 78(3), 973-1006.

Cooper, D., And K. Kuhn (2012): "Communication, renegotiation and the scope for collusion," mimeo.

Dal Bó, P., And G. FrÉchette (2011a): "The evolution of cooperation in infinitely repeated games: Experimental evidence," American Economic Review, 101(1), 411-429.

(2011b): "Strategy choice in the infinitely repeated prisoners dilemma," mimeo.

FARrell, J. (2000): "Renegotiation in repeated oligopoly interaction," in Incentives, Organization, and Public Economics: Papers in Honour of Sir James Mirrlees, ed. by G. Myles, and P. Hammond, pp. 303-322. Oxford University Press.

FArrell, J., And E. Maskin (1989): "Renegotiation in repeated games," Games and Economic Behavior, 1(4), 327-360.

FischbacheR, U. (2007): "z-Tree: Zurich toolbox for ready-made economic experiments.," Experimental Economics, 10(2), 171-178.

Fonseca, M., and H. Normann (2012): "Explicit vs. tacit collusion (the impact of communication in oligopoly experiments)," mimeo.

Greiner, B. (2004): "An online recruitment system for economic experiments," in Forschung und wissenschaftliches Rechnen, ed. by K. Kremer, and V. Macho. GDWG Bericht 63. 
Huck, S., W. Müller, and H. Normann (2002): "To commit or not to commit: Endogenous timing in experimental duopoly markets," Games and Economic Behavior, 38(2), 240-264.

Mailath, G., and L. Samuelson (2005): Repeated Games and Reputation. Oxford University Press.

McCutcheon, B. (1997): "Do meetings in smoke filled rooms facilitate collusion?," Journal of Political Economy, 105(2), 330-350.

Mengel, F., And R. Peeters (2011): "Strategic behavior in repeated voluntary contribution experiments," Journal of Public Economics, 95(1), 143-148.

NowaK, M., And K. Sigmund (1990): "The evolution of stochastic strategies in the prisoner's dilemma.," Acta Applicandae Mathematicae, 20(3), 247-265.

Potters, J., And S. Suetens (2009): "Cooperation in experimental games of complements and substitutes," Review of Economic Studies, 76(3), 1125-1147.

Roth, A., And J. Murnighan (1978): "Equilibrium behavior and repeated play of the prisoner's dilemma," Journal of Mathematical Psychology, 17(2), 189-198.

Selten, R., M. Mitzkewitz, and G. Ulrich (1997): "Duopoly strategies programmed by experienced traders," Econometrica, 65(3), 517-555. 


\section{A Instructions (Strong commitment - strategic complements)}

Part 1

Welcome!

You are about to participate in a session on interactive decision-making. Thank you for agreeing to take part. The session should last 90 to 120 minutes.

You should have already turned off all mobile phones, smart phones, mp3 players and all such devices by now. If not, please do so immediately. These devices must remain switched off throughout the session. Place them in your bag or on the floor besides you. Do not have them in your pocket or on the table in front of you.

The entire session, including all interaction between you and other participants, will take place through the computer. You are not allowed to talk or to communicate with other participants in any other way during the session.

You are asked to abide by these rules throughout the session. Should you fail to do so, we will have to exclude you from this (and future) session(s) and you will not receive any compensation for this session.

We will start with a brief instruction period. Please read these instructions carefully. They are identical for all participants in this session with whom you will interact. If you have any questions about these instructions or at any other time during the experiment, then please raise your hand. One of the experimenters will come to answer your question.

Compensation for participation in this session

In addition to the 3 participation fee, what you will earn from this session will depend on your decisions, the decisions of others and chance. In the instructions and all decision tasks that follow, payoffs are reported in Experimental Currency Units (ECUs). At the end of the experiment, the total amount you have earned will be converted into Euros using the following conversion rate:

$1 \mathrm{ECU}=4$ Eurocents.

The payment takes place in cash at the end of the experiment. Your decisions in the experiment will remain anonymous.

\section{General instructions}

The session is structured as follows:

1. This session consists of 10 matches. At the beginning of each match, you will be randomly paired with another participant.

2. During the match, you will interact repeatedly with this same participant for a number of rounds. 
3. The number of rounds is randomly determined. After each round, there is an $87.5 \%$ chance that the match will continue for at least another round. This is as if we were to roll an 8 -sided die and end if the number 1 came up and continue if 2 through 8 came up. Notice that, if you are in round 2 , the probability that there will be a third round is $87.5 \%$ and if you are in round 9 , the probability that there will be a tenth round is also $87.5 \%$. That is, at any point in the match, the probability that there will be at least one more round is $87.5 \%$. This means that, in expectation, another 8 rounds will follow, irrespective of the number of rounds you have just completed.

4. Once a match ends, you will be matched with a randomly drawn participant for the next match.

\section{Description of a match}

5. During a match you will repeatedly interact with the same participant for a number of rounds. Each round consists of the same decision situation.

6. In this decision situation, you will be asked to choose an action. There are four possible actions: A, B, C or D. The participant you are matched with will also be asked to choose an action. The set of possible actions to choose from is the same for both of you.

7. Your payoff for the round depends on your action and the action of the participant you are matched with. For each possible combination of actions, the table below displays the payoffs for you and the other participant. The rows, which correspond to your action, are labeled in capital letters; the columns, which correspond to the other's action, are labeled in lower-case letters. In each cell your payoff is first (in the darker font) and the other participant's payoff is second (in the lighter font). For example, if your action is B and the other participant's action is c, your payoff is 32 ECU and the other participant's payoff is $40 \mathrm{ECU}$.

\begin{tabular}{|c|c|c|c|c|c|}
\hline & \multicolumn{4}{|c|}{ Other's action } \\
\hline & & a & b & c & d \\
\hline \multirow{4}{*}{$\begin{array}{l}\text { Your } \\
\text { action }\end{array}$} & A & 43,43 & 23,54 & 14,52 & 7,47 \\
\hline & B & 54,23 & 36,36 & 32,40 & 28,37 \\
\hline & $\mathrm{C}$ & 52,14 & 40,32 & 33,33 & 31,32 \\
\hline & $\mathrm{D}$ & 47,7 & 37,28 & 32,31 & 30,30 \\
\hline
\end{tabular}

8. To summarize, in a match you interact repeatedly with the same participant for an unknown number of rounds in the decision situation described above. As described in point 3 above, after every round, there is a $87.5 \%$ chance of another round in this match. 


\section{Your decisions (How actions are chosen)}

At the beginning of a match

9. At the very beginning of every match, you will be asked to specify your initial action and to provide a plan of intended actions. The initial action is the action you choose in the first round of this match. The plan of intended actions determines for each subsequent round which action you intend to choose in response to each possible action choice of the other participant in the previous round.

10. The table below presents an example of a plan of intended actions, as it will be visualized on your screen. In this example, the plan prescribes you to take action D in all rounds immediately following one in which the other participant has taken action a (action $\mathrm{D}$ is checked in column a). In periods immediately following one in which the other participant has chosen action b, the plan prescribes you to take action B (action B is checked in column b) and so forth.

$\begin{aligned} & \text { Your plan } \\
& (\text { example })\end{aligned}$
\begin{tabular}{|c|c|c|c|}
$\mathrm{A} \circ$ & $\mathrm{A} \circ$ & $\mathrm{A} \circ$ & $\mathrm{A} \circ$ \\
\hline $\mathrm{B} \circ$ & $\mathrm{B} \bullet$ & $\mathrm{B} \circ$ & $\mathrm{B} \circ$ \\
\hline $\mathrm{C} \circ$ & $\mathrm{C} \circ$ & $\mathrm{C} \circ$ & $\mathrm{C} \bullet$ \\
\hline $\mathrm{D} \bullet$ & $\mathrm{D} \circ$ & $\mathrm{D} \bullet$ & $\mathrm{D} \circ$ \\
\hline
\end{tabular}

Notice that the table above is just one example of a plan. In the experiment you will be asked to design your own plan.

11. Since it will be costly (see point 15 below) to choose an action different from the one prescribed by your intended plan of action, you are advised to think carefully about how to design your plan.

12. Once you and the participant you are matched with have made your choice of initial action and plan of intended actions, the first round of the sequence of decision situations described above will begin.

\section{During round 1}

13. In the first round, your action choice will be the initial action you just chose.

During later rounds

14. At the beginning of any subsequent round you will be told the prescribed action from your plan of intended actions.

15. You will then be asked to choose your action for the current round. It is possible to choose an action different from the one prescribed by your plan of intended actions. 
However, doing so will cost 3 ECU. Note also that you will need to select this action and click on the "OK" button within the time limit shown on your screen; otherwise your prescribed action will be chosen.

At the end of each round

16. At the end of each round you will receive feedback on your action chosen, the action chosen by the other participant and your payoffs as well as about any costs incurred for deviating from the plan of intended actions.

\section{The end of the session}

17. After a match is finished, you will be randomly paired for a new match. This session consists of 10 such matches.

18. In each of the 10 matches, your payoff starts at 0 and from there accumulates until the end of your match. At the end of the session - after the tenth match - one match will be selected at random. The payoff you gained during the selected match will be used to calculate your final payoff.

\section{Control Questions}

Please read through the following and answer the questions. When you have finished answering these questions, please raise your hand.

Assume you specified action A as initial action and the following plan of intended actions:

\begin{tabular}{|c|c|c|c|c|}
\hline \multirow[t]{5}{*}{ Your plan } & a & b & \multicolumn{2}{|r|}{ d } \\
\hline & $\mathrm{A} \bullet$ & $\mathrm{A} \circ$ & $\mathrm{A} \bullet$ & $\mathrm{A} \circ$ \\
\hline & $\mathrm{B} \circ$ & $\mathrm{B} \bullet$ & $\mathrm{B} \circ$ & $\mathrm{B} \bullet$ \\
\hline & $\mathrm{C} \circ$ & $\mathrm{C} \circ$ & $\mathrm{C} \circ$ & $\mathrm{C} \circ$ \\
\hline & $\mathrm{D} \circ$ & $\mathrm{D} \circ$ & $\mathrm{D} \circ$ & $\mathrm{D} \circ$ \\
\hline
\end{tabular}

Suppose that the other participant chooses action b in the first round.

1. What is your payoff in the first round?

2. What is the other participant's payoff in the first round?

3. Which action does your plan prescribe you to choose in the second round?

Assume that you choose the prescribed action in the second round. Suppose that the other participant chooses action $\mathrm{d}$ in the second round.

4. What is your payoff in the second round?

5. Which action will you be prescribed to choose in the third round? 
True or False?

Please answer whether the following statements are true or false:

6. The longer a match has been going on the more likely it is to end.

7. Each round I can choose the action I want.

8. I can modify my plan of intended action after each round within a match.

9. I am matched with the same participant during the entire session.

10. I am matched with the same participant during each match.

\section{Part 2}

\section{Control Questions - Answers}

1. In the first round, if you choose A and the other participant chooses $b$, then your payoff is 23 .

2. In the first round, if you choose A and the other participant chooses b, then the other participant's payoff is 54 .

3. The other participant chose $\mathrm{b}$ in the first round. Reading column b of your plan gives you a prescribed action of B.

4. In the second round, if you choose B and the other participant chooses d, then your payoff is 28 .

5. The other participant chose $\mathrm{d}$ in the second round. Reading column d of your plan gives you a prescribed action of $\mathrm{B}$.

True or False? - Answers

6. False: at any point in the match, the probability that there will be at least one more round is $87.5 \%$.

7. True: In any round, you can choose the action you would like. In particular, it is possible to choose an action different from the one prescribed by your plan of intended actions. However, doing so will cost 3 ECU.

8. False: you can only modify your plan of intended actions at the beginning of a match.

9. False: once a match ends, you will be matched with a randomly drawn participant for the next match.

10. True: in a match you interact repeatedly with the same participant 


\section{Summary}

1. At the beginning of a match, you choose your initial action and your plan of intended actions.

2. Every round (except for the first round) your plan prescribes an action that depends on the action of the other participant in the previous round.

3. In any round (except for the first round), you can either choose the prescribed action or choose another action. Choosing an action which is different from your prescribed action has a cost of 3 ECU.

4. The length of a match is randomly determined. After each round, there is an $87.5 \%$ chance that the match will continue for at least one more round. You will play with the same person for the entire match.

5. After a match is finished, you will be randomly paired for a new match. This session consists of 10 such matches. 


\section{B The hot treatment}

Subsection 4.3 provides a good indicator that participants did not feel restricted in their choice of strategies as they do use reasonable machines and employ one-shot deviations infrequently. To get a precise measure of whether imposing the small cost for one-shot deviations and machine modifications distorts decisions, additional hot treatment were conducted. In these treatments, the cost of one-shot deviations were set to zero so that any strategy (even the most erratic ones) can be played at no cost.

Figure 6 compares rates of action choice across the four treatments for both strategic substitutes and complements. The top panel gives the rates across all stages, the lower panel for only the initial stage. The rates of action choices in the hot treatments are very similar to those observed in the unilateral treatments. Furthermore, the observed comparative static across types of strategic interaction is the same between these two treatments.

Given the evidence above that observed behavior in the hot treatments is comparable to that in the unilateral treatments, Table 9 and Figure 7 replicate the collusion-choice regression analysis of Section 4 for the hot treatment, using the unilateral variation as the base observation. Table 10 and Figure 8 repeat the analysis for the efficiency measure. As can be most clearly seen in the graphs, behavior in the hot treatment is remarkably similar to that in the unilateral treatment in all aspects except the across match development in the case of strategic substitutes. Here, cooperative behavior starts a little bit higher and increases at a slower rate in the hot treatment compared to the unilateral treatment. However, it should be emphasized that the across match evolution of cooperative behavior in both treatments would not be statistically different from that observed in the strong commitment treatment with strategic substitutes, especially when looking at the efficiency measure.

\begin{tabular}{|c|c|c|c|c|}
\hline \multirow[b]{3}{*}{ Hot } & \multicolumn{2}{|c|}{ Substitutes } & \multicolumn{2}{|c|}{ Complements } \\
\hline & (1) & (2) & (1) & (2) \\
\hline & $-0.51 \quad(0.246)$ & $-1.30^{* *}(0.042)$ & $0.70^{*} \quad(0.052)$ & $1.08 \quad(0.115)$ \\
\hline Stage & $-0.09^{* * *}(0.000)$ & $-0.08^{* * *}(0.000)$ & $-0.12^{* * *}(0.000)$ & $-0.10^{* * *}(0.000)$ \\
\hline Hot x Stage & $0.02 \quad(0.376)$ & $0.02 \quad(0.524)$ & $0.02 \quad(0.661)$ & $0.00 \quad(0.893)$ \\
\hline Match & & $0.11 \quad(0.440)$ & & $0.48^{* * *}(0.000)$ \\
\hline Hot x Match & & $0.30^{* *}(0.019)$ & & $-0.11 \quad(0.547)$ \\
\hline Constant & $-0.94^{* * *}(0.000)$ & $-1.14^{* * *}(0.006)$ & $-1.40^{* * *}(0.008)$ & $-2.58^{* * *}(0.000)$ \\
\hline Included Matches & $7-10$ & $7-10$ & $7-10$ & $7-10$ \\
\hline Included Stages & $1-12$ & $1-12$ & $1-12$ & $1-12$ \\
\hline M-S Dummies & Yes & Yes & Yes & Yes \\
\hline Cluster VCE & Yes & Yes & Yes & Yes \\
\hline
\end{tabular}

Table 9: Logit regression of the probability of choosing the collusive action. 


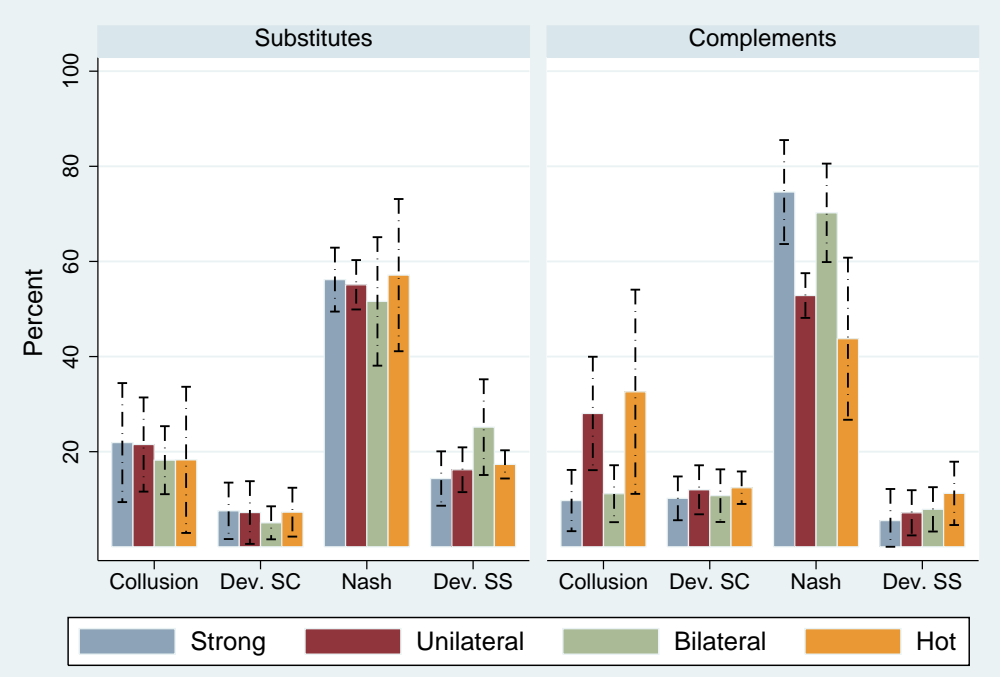

Data from matches 7-10. Dashed lines indicate cluster-robust 95\% confidence intervals.

(a) In all stages.

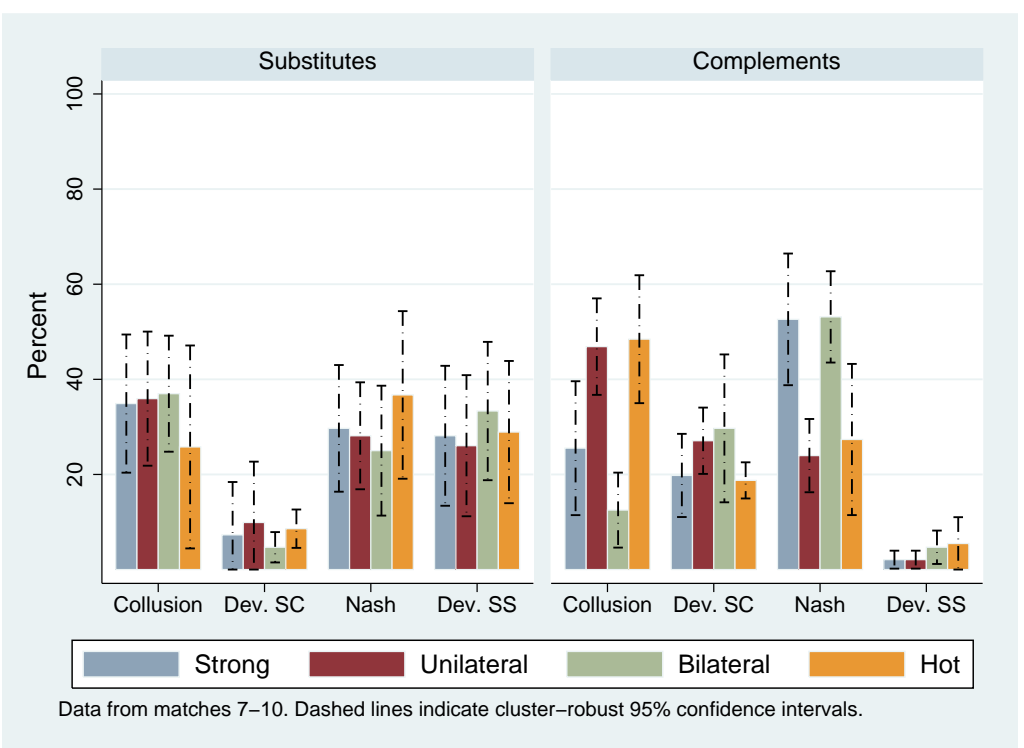

(b) Initial choices only.

Figure 6: Average stage-game choices. 


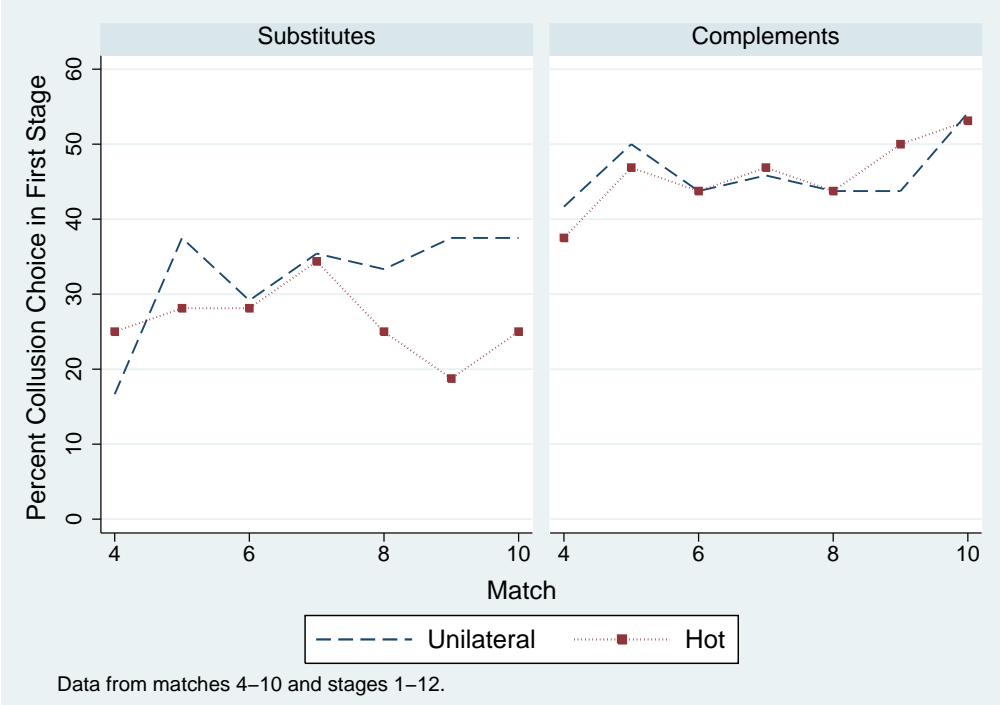

(a) Collusion choice across matches.

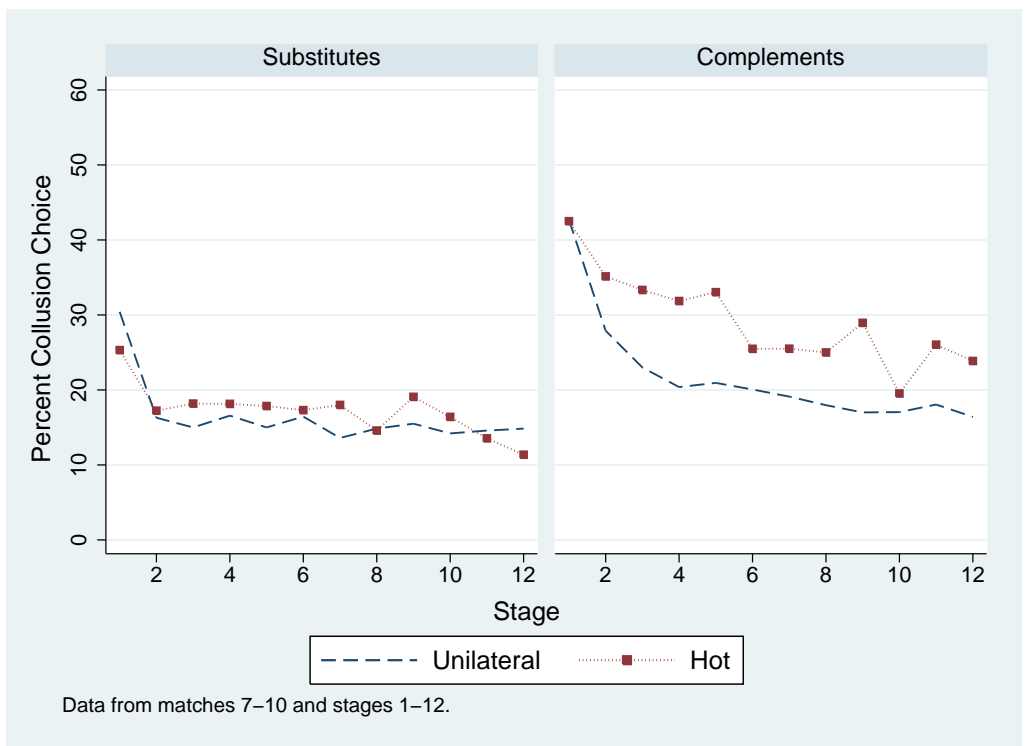

(b) Collusion choice within matches.

Figure 7: Collusion choice in the unilateral and hot treatments. 


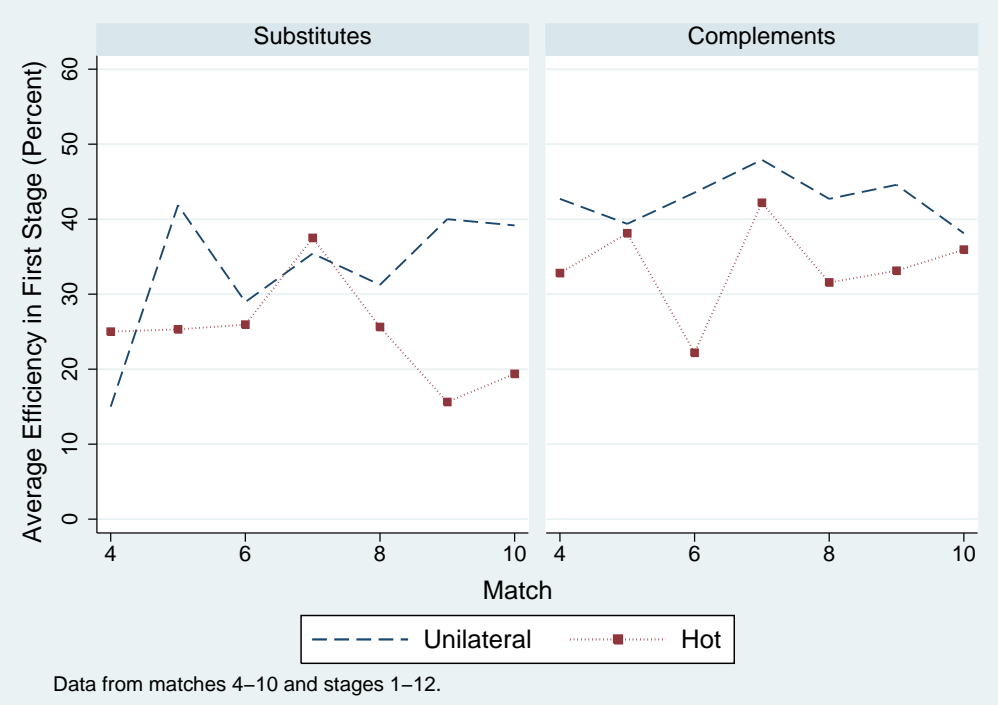

(a) Efficiency across matches.

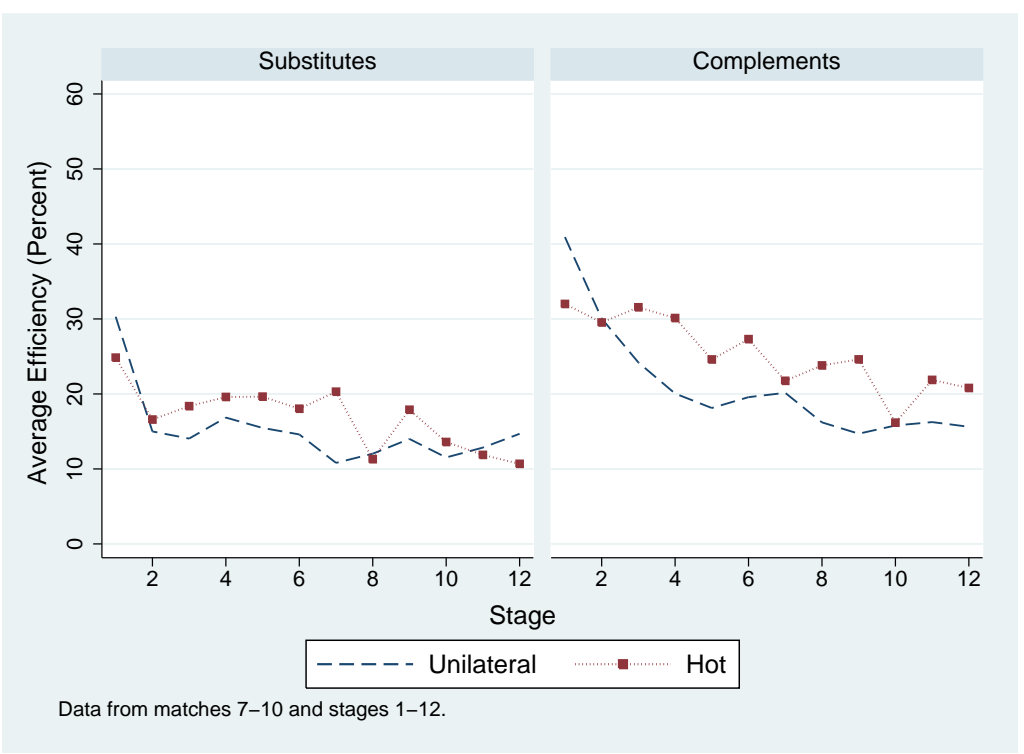

(b) Efficiency within matches.

Figure 8: Efficiency in the unilateral and hot treatments. 


\begin{tabular}{|c|c|c|c|c|}
\hline \multirow[b]{3}{*}{ Hot } & \multicolumn{2}{|c|}{ Substitutes } & \multicolumn{2}{|c|}{ Compliments } \\
\hline & (1) & $(2)$ & (1) & $(2)$ \\
\hline & $-0.06 \quad(0.552)$ & $-0.06 \quad(0.643)$ & $0.11 \quad(0.202)$ & $0.10 \quad(0.501)$ \\
\hline Stage & $-0.01^{* * *}(0.000)$ & $-0.01^{* * *}(0.002)$ & $-0.02^{* * *}(0.001)$ & $-0.02^{* * *}(0.004)$ \\
\hline Hot x Stage & $-0.00 \quad(0.994)$ & $-0.00 \quad(0.964)$ & $-0.00 \quad(0.885)$ & $-0.00 \quad(0.826)$ \\
\hline Match & & $(0.257)$ & & $0.07^{* * *}(0.000)$ \\
\hline Hot x Match & & $0.00 \quad(0.969)$ & & $0.01 \quad(0.908)$ \\
\hline Constant & $0.30^{* * *}(0.000)$ & $0.23^{* *} \quad(0.020)$ & $0.22^{* * *}(0.006)$ & $(0.471)$ \\
\hline Included Matches & $7-10$ & $7-10$ & $7-10$ & $7-10$ \\
\hline Included Stages & $1-12$ & $1-12$ & $1-12$ & $1-12$ \\
\hline M-S Dummies & Yes & Yes & Yes & Yes \\
\hline Cluster VCE & Yes & Yes & Yes & Yes \\
\hline
\end{tabular}

Table 10: Linear random-effects regression of payoff efficiency in the stage game.

Behavior under the hot treatments is by and large very similar to behavior in the corresponding unilateral treatments. This result lends support to the conclusion that participants did not feel overly constrained in their strategies by the costs that are imposed by one-shot deviations. 


\section{Controlling for path dependency}

In order to isolate the impact of the responsive part of the strategies from initial choices, we compute the invariant distribution over actions of the Markov chain as specified by the dynamic responses. The invariant distribution tells us with which probabilities the actions will be chosen in the long run if play continues as it is observed in our experimental sessions, regardless of the initial choices. We compute these invariant distributions using the transition probabilities as defined by (1) the average initial machine, (2) the average over chosen actions in response to rival's actions, and (3) the average chosen actions in response to outcomes. Note that by taking averages over the average behavior of an individual in a match (of the last four matches only), we disregard the heterogeneity that is clearly present in our data (which is more pronounced between individuals than between matches). Although the job is in principle better done when properly controlling for heterogeneity in behavior, it is certainly computationally more involved and (as we believe) not needed for our illustrative purposes. The invariant distributions obtained for the different treatments using the three different specifications of the Markov chain are presented in Table 11.

\begin{tabular}{|c|c|c|c|c|c|c|c|}
\hline \multirow[b]{2}{*}{ Transitions } & \multirow[b]{2}{*}{ Action } & \multicolumn{3}{|c|}{ Substitutes } & \multicolumn{3}{|c|}{ Complements } \\
\hline & & Strong & Unilateral & Bilateral & Strong & Unilateral & Bilateral \\
\hline Initial & A & 0.0372 & 0.0916 & 0.0630 & 0.0086 & 0.1416 & 0.0153 \\
\hline \multirow[t]{3}{*}{ Machines } & $\mathrm{B}$ & 0.0760 & 0.0523 & 0.0709 & 0.0633 & 0.1146 & 0.0701 \\
\hline & $\mathrm{C}$ & 0.7834 & 0.6889 & 0.6414 & 0.8769 & 0.6531 & 0.8410 \\
\hline & $\mathrm{D}$ & 0.1034 & 0.1672 & 0.2247 & 0.0511 & 0.0907 & 0.0736 \\
\hline \multirow{4}{*}{$\begin{array}{l}\text { Realized } \\
\text { Actions } \\
\text { (actions) }\end{array}$} & $\mathrm{A}$ & 0.1252 & 0.1430 & 0.1210 & 0.0561 & 0.0989 & 0.0528 \\
\hline & B & 0.0997 & 0.0543 & 0.0560 & 0.1105 & 0.1062 & 0.1021 \\
\hline & $\mathrm{C}$ & 0.6361 & 0.6235 & 0.5879 & 0.7735 & 0.6691 & 0.7703 \\
\hline & $\mathrm{D}$ & 0.1390 & 0.1792 & 0.2351 & 0.0599 & 0.1258 & 0.0748 \\
\hline \multirow{4}{*}{$\begin{array}{l}\text { Realized } \\
\text { Actions } \\
\text { (outcomes) }\end{array}$} & A & 0.1258 & 0.1095 & 0.1076 & 0.0473 & 0.0552 & 0.0471 \\
\hline & B & 0.0968 & 0.0585 & 0.0630 & 0.0887 & 0.0948 & 0.0646 \\
\hline & $\mathrm{C}$ & 0.6580 & 0.6826 & 0.6130 & 0.7881 & 0.7006 & 0.7669 \\
\hline & $\mathrm{D}$ & 0.1194 & 0.1494 & 0.2163 & 0.0759 & 0.1494 & 0.1215 \\
\hline
\end{tabular}

Table 11: Invariant distribution.

The differences in long-run distributions across treatments are quite in line with those of the percentages as presented in Figure 1. The logit regressions presented in Table 4 (see also Figure 2(a)) show that in case of strategic complementarities a higher level of collusion is obtained when unilateral modifications of the dynamic response is allowed. The invariant distributions show a consistent picture and that this effect is not only caused by initial choices (see Figures 4 and 2(b)).

Apart from Complements-Unilateral, the weight on the top two actions (A and B) is smaller and that on the lower two actions $(\mathrm{C}$ and $\mathrm{D})$ is larger using the realized actions, which indicates that one-shot deviations and machine modifications are mainly used to escape profit eroding states in favor for collusive ones. 
Table 12 presents the persistence of the collusive outcome, the Nash outcome, the top two actions and the lower two actions. For the single state outcomes the persistence is the probability that the state is not left in the next stage given that it is reached. For the sets of states these probabilities are weighted by the invariant distribution of the Markov process over outcomes (to properly account for all states within a set not being more likely being reached). Again, we derive the probabilities in the three alternative ways as before.

\begin{tabular}{|c|c|c|c|c|c|c|c|}
\hline \multirow[b]{2}{*}{ Transitions } & \multirow[b]{2}{*}{ Outcome } & \multicolumn{3}{|c|}{ Substitutes } & \multicolumn{3}{|c|}{ Complements } \\
\hline & & Strong & Unilateral & Bilateral & Strong & Unilateral & Bilateral \\
\hline Initial & $(\mathrm{A}, \mathrm{A})$ & 0.1567 & 0.1218 & 0.2296 & 0.1111 & 0.2659 & 0.0913 \\
\hline \multirow[t]{3}{*}{ Machines } & $(\mathrm{C}, \mathrm{C})$ & 0.6944 & 0.5703 & 0.5393 & 0.7932 & 0.6104 & 0.7565 \\
\hline & $(\mathrm{AB}, \mathrm{AB})$ & 0.1106 & 0.1258 & 0.1690 & 0.0782 & 0.4036 & 0.1529 \\
\hline & $(\mathrm{CD}, \mathrm{CD})$ & 0.8369 & 0.7948 & 0.8262 & 0.8914 & 0.7645 & 0.8895 \\
\hline \multirow{4}{*}{$\begin{array}{l}\text { Realized } \\
\text { Actions } \\
\text { (actions) }\end{array}$} & $(\mathrm{A}, \mathrm{A})$ & 0.2004 & 0.2440 & 0.1757 & 0.1494 & 0.3285 & 0.1715 \\
\hline & $(\mathrm{C}, \mathrm{C})$ & 0.5339 & 0.5405 & 0.5133 & 0.6934 & 0.5989 & 0.6980 \\
\hline & $(\mathrm{AB}, \mathrm{AB})$ & 0.1619 & 0.2217 & 0.1854 & 0.2014 & 0.3008 & 0.2891 \\
\hline & $(\mathrm{CD}, \mathrm{CD})$ & 0.6834 & 0.7568 & 0.7701 & 0.7918 & 0.7806 & 0.8377 \\
\hline \multirow{4}{*}{$\begin{array}{l}\text { Realized } \\
\text { Actions } \\
\text { (outcomes) }\end{array}$} & $(\mathrm{A}, \mathrm{A})$ & $\overline{0.8422}$ & 0.7204 & 0.5814 & $\overline{0.7008}$ & 0.8580 & 0.8789 \\
\hline & $(\mathrm{C}, \mathrm{C})$ & 0.6809 & 0.7514 & 0.5993 & 0.7987 & 0.7022 & 0.8010 \\
\hline & $(\mathrm{AB}, \mathrm{AB})$ & 0.7071 & 0.5950 & 0.5530 & 0.4774 & 0.6647 & 0.7321 \\
\hline & $(\mathrm{CD}, \mathrm{CD})$ & 0.7924 & 0.8670 & 0.8062 & 0.8763 & 0.8427 & 0.9207 \\
\hline
\end{tabular}

Table 12: Direct recurring transitions.

It is apparent that the persistence probabilities of the collusive outcome are substantially larger when applying the data of how outcomes are translated into actions. This shows us that one-shot deviations and dynamic response modifications are used to sustain cooperation. Application of outcome to action data also increases the persistence probabilities of the static Nash outcome when dynamic responses can be revised, but not when only one-shot deviations are possible. This indicates that in a setting with less strategic commitment, and hence better possibilities to renegotiate, punishments are sustained by means of one-shot deviations and dynamic response modifications. If anything, this provides evidence against the idea of renegotiation playing an important role. This means that the idea of renegotiation is also not learned (or should be unlearned) during the sessions and can be expected to be anticipated and absorbed in initial choices. 


\section{Additional material}

\section{D.1 Figures}

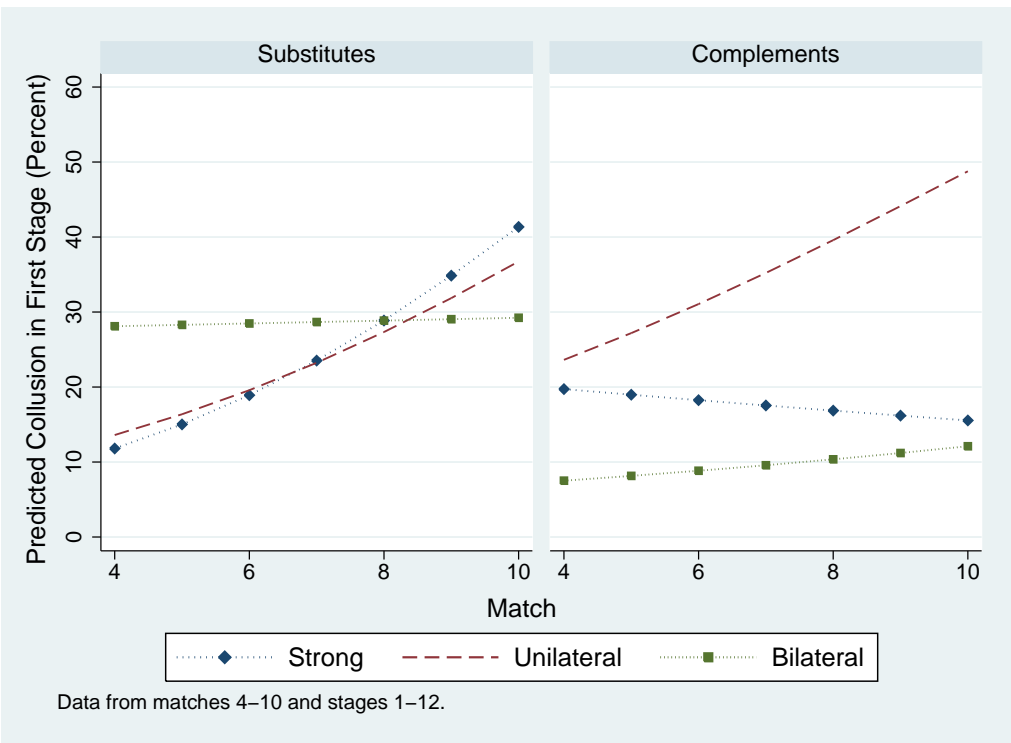

(a) Collusion choice across matches.

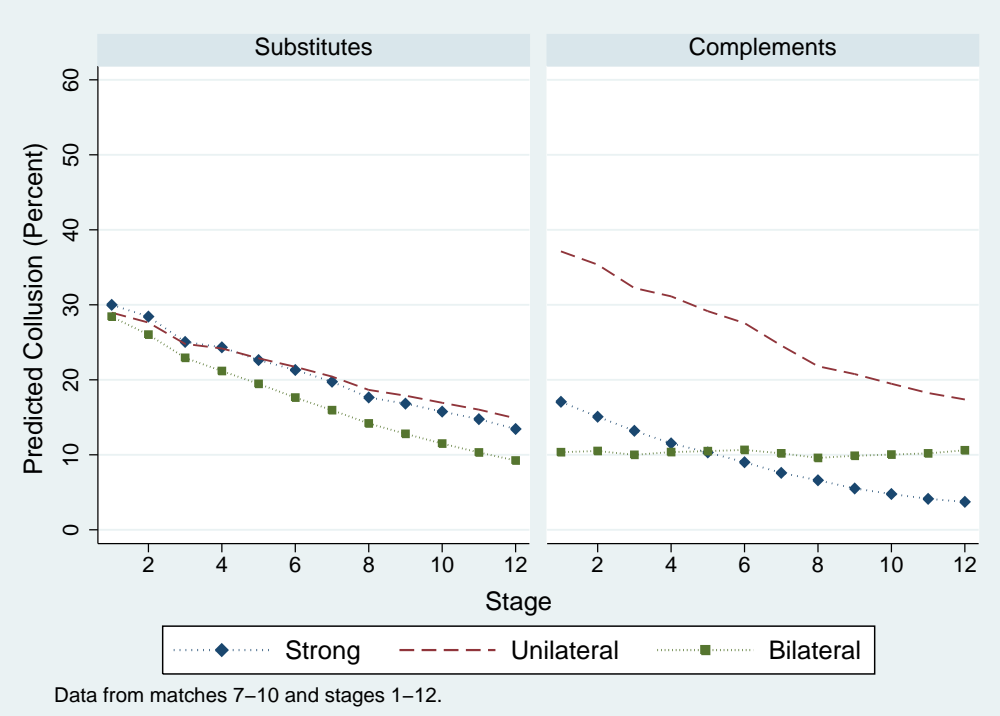

(b) Collusion choice within matches.

Figure 9: The effect of strategic commitment on collusion with strategic complements and substitutes: predicted values from a logit regression. 

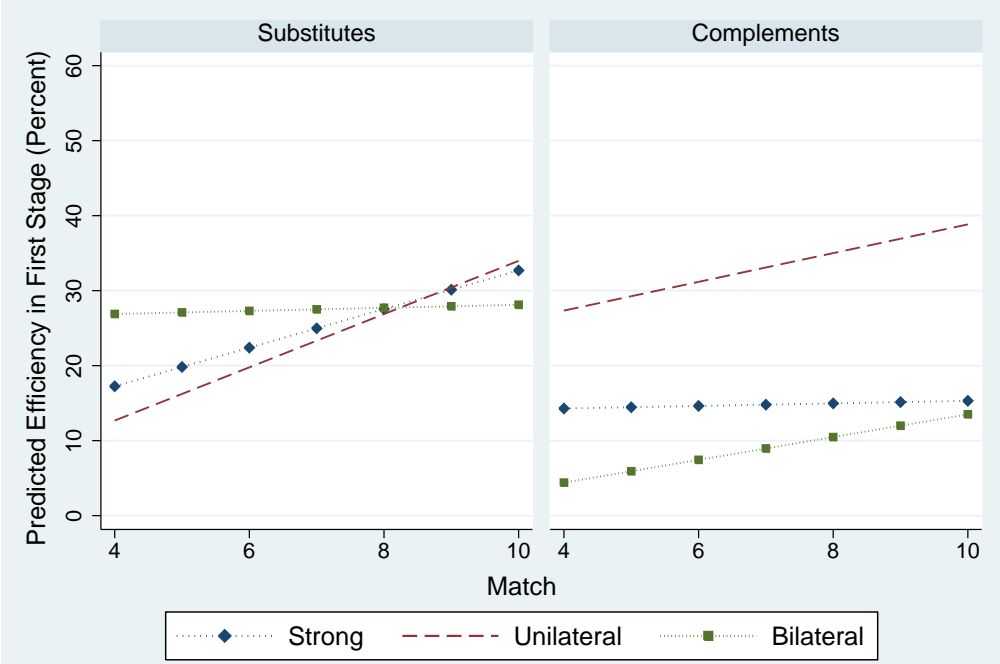

Data from matches $4-10$ and stages $1-12$.

(a) Efficiency across matches.

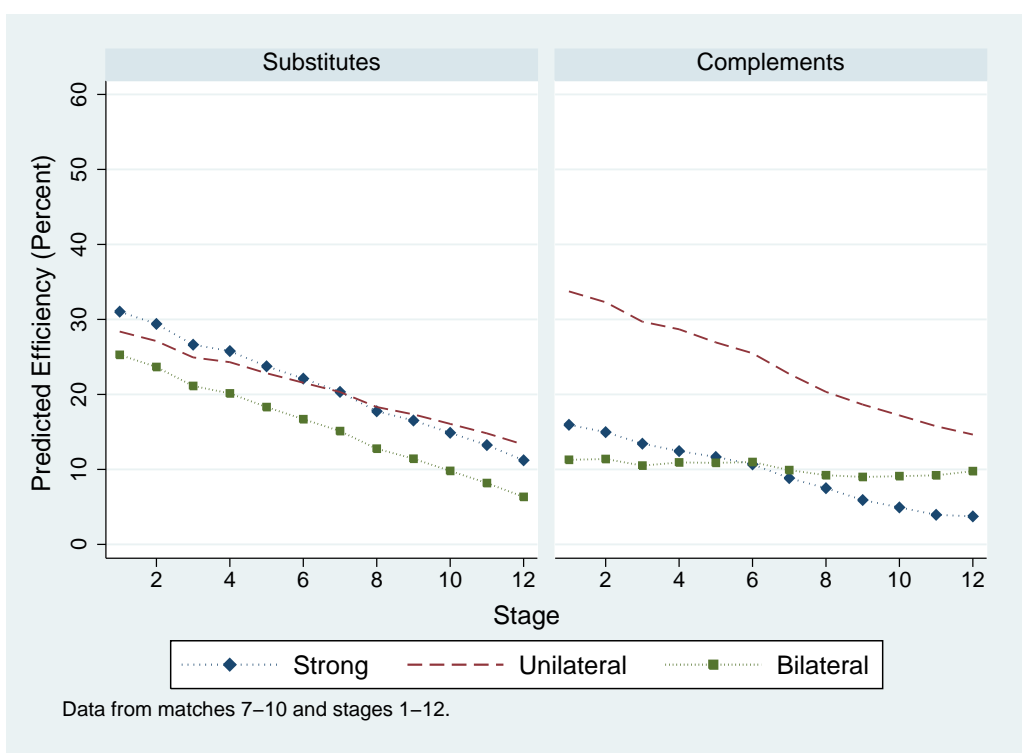

(b) Efficiency within matches.

Figure 10: The effect of strategic commitment on efficiency with strategic complements and substitutes: predicted values from a linear random-effects regression. 


\section{D.2 Tables}

\begin{tabular}{|c|c|c|c|c|c|c|c|c|}
\hline & \multicolumn{4}{|c|}{ Substitutes } & \multicolumn{4}{|c|}{ Complements } \\
\hline & (1) & $(2)$ & (3) & (4) & (1) & $(2)$ & (3) & (4) \\
\hline Unilateral & $\begin{array}{l}-0.07 \\
(0.873)\end{array}$ & $\begin{array}{l}-0.07 \\
(0.866)\end{array}$ & $\begin{array}{c}0.24 \\
(0.670)\end{array}$ & $\begin{array}{c}0.24 \\
(0.636)\end{array}$ & $\begin{array}{c}1.05^{* *} \\
(0.037)\end{array}$ & $\begin{array}{c}1.00^{*} \\
(0.061)\end{array}$ & $\begin{array}{c}-0.28 \\
(0.670)\end{array}$ & $\begin{array}{c}-0.27 \\
(0.750)\end{array}$ \\
\hline Bilateral & $\begin{array}{c}-0.05 \\
(0.879)\end{array}$ & $\begin{array}{c}-0.04 \\
(0.909)\end{array}$ & $\begin{array}{c}0.99^{* *} \\
(0.038)\end{array}$ & $\begin{array}{c}0.98^{*} \\
(0.067)\end{array}$ & $\begin{array}{l}-0.76 \\
(0.241)\end{array}$ & $\begin{array}{c}-0.74 \\
(0.252)\end{array}$ & $\begin{array}{c}-1.91 \\
(0.109)\end{array}$ & $\begin{array}{c}-1.82 \\
(0.118)\end{array}$ \\
\hline Stage & $\begin{array}{c}-0.09^{* * *} \\
(0.000)\end{array}$ & $\begin{array}{c}-0.09^{* * *} \\
(0.001)\end{array}$ & $\begin{array}{c}-0.08^{* * *} \\
(0.000)\end{array}$ & $\begin{array}{c}-0.08^{* * *} \\
(0.000)\end{array}$ & $\begin{array}{c}-0.15^{*} \\
(0.087)\end{array}$ & $\begin{array}{c}-0.15^{*} \\
(0.082)\end{array}$ & $\begin{array}{c}-0.15^{*} \\
(0.098)\end{array}$ & $\begin{array}{c}-0.16^{*} \\
(0.087)\end{array}$ \\
\hline Unilateral x Stage & $\begin{array}{c}0.02 \\
(0.648)\end{array}$ & $\begin{array}{c}0.02 \\
(0.640)\end{array}$ & $\begin{array}{c}0.01 \\
(0.718)\end{array}$ & $\begin{array}{c}0.01 \\
(0.676)\end{array}$ & $\begin{array}{c}0.05 \\
(0.557)\end{array}$ & $\begin{array}{c}0.06 \\
(0.552)\end{array}$ & $\begin{array}{c}0.07 \\
(0.470)\end{array}$ & $\begin{array}{c}0.07 \\
(0.479)\end{array}$ \\
\hline Bilateral x Stage & $\begin{array}{c}-0.03 \\
(0.233)\end{array}$ & $\begin{array}{c}-0.03 \\
(0.282)\end{array}$ & $\begin{array}{c}-0.04^{*} \\
(0.070)\end{array}$ & $\begin{array}{c}-0.04 \\
(0.112)\end{array}$ & $\begin{array}{c}0.16 \\
(0.115)\end{array}$ & $\begin{array}{c}0.15 \\
(0.122)\end{array}$ & $\begin{array}{c}0.17 \\
(0.109)\end{array}$ & $\begin{array}{c}0.16 \\
(0.118)\end{array}$ \\
\hline Match & & & $\begin{array}{c}0.35^{* * *} \\
(0.000)\end{array}$ & $\begin{array}{c}0.30^{* * *} \\
(0.003)\end{array}$ & & & $\begin{array}{c}-0.10 \\
(0.361)\end{array}$ & $\begin{array}{c}-0.14 \\
(0.312)\end{array}$ \\
\hline Unilateral x Match & & & $\begin{array}{c}-0.12 \\
(0.435)\end{array}$ & $\begin{array}{c}-0.12 \\
(0.484)\end{array}$ & & & $\begin{array}{c}0.52^{* * *} \\
(0.000)\end{array}$ & $\begin{array}{c}0.50^{* * *} \\
(0.006)\end{array}$ \\
\hline Bilateral x Match & & & $\begin{array}{r}-0.40^{* *} \\
(0.021)\end{array}$ & $\begin{array}{r}-0.40^{* *} \\
(0.031)\end{array}$ & & & $\begin{array}{c}0.44^{*} \\
(0.093)\end{array}$ & $\begin{array}{c}0.42^{*} \\
(0.068)\end{array}$ \\
\hline Constant & $\begin{array}{c}-0.60^{* * *} \\
(0.002) \\
\end{array}$ & $\begin{array}{c}-0.77^{* * *} \\
(0.008)\end{array}$ & $\begin{array}{c}-1.45^{* * *} \\
(0.000)\end{array}$ & $\begin{array}{c}-1.54^{* * *} \\
(0.000)\end{array}$ & $\begin{array}{c}-2.25^{* * *} \\
(0.000)\end{array}$ & $\begin{array}{c}-1.42^{* * *} \\
(0.004)\end{array}$ & $\begin{array}{c}-1.92^{* * *} \\
(0.003)\end{array}$ & $\begin{array}{c}-1.07 \\
(0.164)\end{array}$ \\
\hline Included Matches & $7-10$ & $7-10$ & $7-10$ & $7-10$ & $7-10$ & $7-10$ & $7-10$ & $7-10$ \\
\hline Included Stages & $1-12$ & $1-12$ & $1-12$ & $1-12$ & $1-12$ & $1-12$ & $1-12$ & $1-12$ \\
\hline M-S Dummies & Yes & No & Yes & No & Yes & No & Yes & No \\
\hline Cluster VCE & Yes & Yes & Yes & Yes & Yes & Yes & Yes & Yes \\
\hline
\end{tabular}

Table 13: Robustness check on the inclusion of match-stage composition dummies. The baseline case is the strong commitment treatment. Specifications 2 and 4 are the same as the reported specifications, 1 and 3, but without the match-stage composition dummies. ${ }^{* * *} 1 \%$, ${ }^{* *} 5 \%,{ }^{*} 10 \%$ significance. 


\begin{tabular}{|c|c|c|c|c|c|c|}
\hline & \multicolumn{3}{|c|}{ Substitutes } & \multicolumn{3}{|c|}{ Complements } \\
\hline & (1) & $(2)$ & $(3)$ & (1) & $(2)$ & $(3)$ \\
\hline Unilateral & $\begin{array}{c}0.24 \\
(0.670)\end{array}$ & $\begin{array}{c}0.19 \\
(0.680)\end{array}$ & $\begin{array}{c}-0.94 \\
(0.194)\end{array}$ & $\begin{array}{c}-0.28 \\
(0.670)\end{array}$ & $\begin{array}{c}-0.01 \\
(0.989)\end{array}$ & $\begin{array}{c}1.04 \\
(0.214)\end{array}$ \\
\hline Bilateral & $\begin{array}{c}0.99^{* *} \\
(0.038)\end{array}$ & $\begin{array}{l}1.37^{* * *} \\
(0.003)\end{array}$ & $\begin{array}{c}-0.07 \\
(0.899)\end{array}$ & $\begin{array}{c}-1.91 \\
(0.109)\end{array}$ & $\begin{array}{c}-1.42^{*} \\
(0.076)\end{array}$ & $\begin{array}{l}-1.32 \\
(0.131)\end{array}$ \\
\hline Stage & $\begin{array}{c}-0.08^{* * *} \\
(0.000)\end{array}$ & $\begin{array}{c}-0.11^{* * *} \\
(0.000)\end{array}$ & $\begin{array}{c}-0.23^{* * *} \\
(0.000)\end{array}$ & $\begin{array}{c}-0.15^{*} \\
(0.098)\end{array}$ & $\begin{array}{c}-0.14^{* * *} \\
(0.004)\end{array}$ & $\begin{array}{c}-0.10^{*} \\
(0.067)\end{array}$ \\
\hline Unilateral x Stage & $\begin{array}{c}0.01 \\
(0.718)\end{array}$ & $\begin{array}{c}0.03 \\
(0.358)\end{array}$ & $\begin{array}{c}0.12^{*} \\
(0.089)\end{array}$ & $\begin{array}{l}0.07 \\
(0.470)\end{array}$ & $\begin{array}{c}0.00 \\
(0.946)\end{array}$ & $\begin{array}{c}-0.09 \\
(0.287)\end{array}$ \\
\hline Bilateral x Stage & $\begin{array}{c}-0.04^{*} \\
(0.070)\end{array}$ & $\begin{array}{c}-0.02 \\
(0.562)\end{array}$ & $\begin{array}{c}0.08 \\
(0.215)\end{array}$ & $\begin{array}{c}0.17 \\
(0.109)\end{array}$ & $\begin{array}{l}0.15^{* * *} \\
(0.003)\end{array}$ & $\begin{array}{c}0.15^{*} \\
(0.098)\end{array}$ \\
\hline Match & $\begin{array}{c}0.35^{* * *} \\
(0.000)\end{array}$ & $\begin{array}{c}0.28^{* * *} \\
(0.000)\end{array}$ & $\begin{array}{c}-0.09 \\
(0.717)\end{array}$ & $\begin{array}{c}-0.10 \\
(0.361)\end{array}$ & $\begin{array}{c}-0.05 \\
(0.571)\end{array}$ & $\begin{array}{c}0.23 \\
(0.326)\end{array}$ \\
\hline Unilateral x Match & $\begin{array}{l}-0.12 \\
(0.435)\end{array}$ & $\begin{array}{l}-0.06 \\
(0.527)\end{array}$ & $\begin{array}{l}0.36 \\
(0.270)\end{array}$ & $\begin{array}{l}0.52^{* * *} \\
(0.000)\end{array}$ & $\begin{array}{c}0.24^{* *} \\
(0.041)\end{array}$ & $\begin{array}{c}-0.03 \\
(0.921)\end{array}$ \\
\hline Bilateral x Match & $\begin{array}{r}-0.40^{* *} \\
(0.021)\end{array}$ & $\begin{array}{c}-0.27^{* * *} \\
(0.009)\end{array}$ & $\begin{array}{c}0.28 \\
(0.356)\end{array}$ & $\begin{array}{c}0.44^{*} \\
(0.093)\end{array}$ & $\begin{array}{c}0.14 \\
(0.183)\end{array}$ & $\begin{array}{c}0.15 \\
(0.697)\end{array}$ \\
\hline Constant & $\begin{array}{c}-1.45^{* * *} \\
(0.000)\end{array}$ & $\begin{array}{c}-1.97^{* * *} \\
(0.000)\end{array}$ & $\begin{array}{c}-0.82 \\
(0.144)\end{array}$ & $\begin{array}{c}-1.92^{* * *} \\
(0.003)\end{array}$ & $\begin{array}{c}-1.89^{* * *} \\
(0.002)\end{array}$ & $\begin{array}{c}-2.38^{* * *} \\
(0.000)\end{array}$ \\
\hline Included Matches & $7-10$ & $4-10$ & $4-6$ & $7-10$ & $4-10$ & $4-6$ \\
\hline Included Stages & $1-12$ & $1-12$ & $1-12$ & $1-12$ & $1-12$ & $1-12$ \\
\hline M-S Dummies & Yes & Yes & Yes & Yes & Yes & Yes \\
\hline Cluster VCE & Yes & Yes & Yes & Yes & Yes & Yes \\
\hline
\end{tabular}

Table 14: Robustness check on the data sub-sample. The baseline case is the strong commitment treatment. Specifications 2 and 3 are the same as the reported specification, 1, except use the final two-thirds and the middle third sub-samples. ${ }^{* *} 1 \%,{ }^{* *} 5 \%,{ }^{*} 10 \%$ significance.

\begin{tabular}{|c|c|c|c|c|c|c|}
\hline \multirow[b]{3}{*}{ Unilateral } & \multicolumn{2}{|c|}{ Substitutes } & \multicolumn{4}{|c|}{ Complements } \\
\hline & (1) & $(2)$ & \multicolumn{2}{|c|}{ (1) } & \multicolumn{2}{|c|}{$(2)$} \\
\hline & $0.24 \quad(0.670)$ & $0.02 \quad(0.838)$ & -0.28 & $(0.670)$ & 0.02 & $(0.720)$ \\
\hline Bilateral & $0.99^{* *} \quad(0.038)$ & $0.05 \quad(0.312)$ & -1.91 & $(0.109)$ & -0.09 & $(0.291)$ \\
\hline Stage & $-0.08^{* * *}(0.000)$ & $-0.02^{* * *}(0.000)$ & $-0.15^{*}$ & $(0.098)$ & $-0.01^{*}$ & $(0.096)$ \\
\hline Unilateral x Stage & $0.01 \quad(0.718)$ & $0.00 \quad(0.371)$ & 0.07 & $(0.470)$ & -0.01 & $(0.354)$ \\
\hline Bilateral x Stage & $-0.04^{*} \quad(0.070)$ & $0.00 \quad(0.850)$ & 0.17 & $(0.109)$ & 0.01 & $(0.190)$ \\
\hline Match & $0.35^{* * *}(0.000)$ & $0.05^{* * *}(0.005)$ & -0.10 & $(0.361)$ & 0.01 & $(0.593)$ \\
\hline Unilateral x Match & $-0.12 \quad(0.435)$ & $-0.01 \quad(0.693)$ & $0.52^{* * *}$ & $(0.000)$ & $0.07^{* * *}$ & $(0.000)$ \\
\hline Bilateral x Match & $-0.40^{* *} \quad(0.021)$ & $-0.03 \quad(0.237)$ & $0.44^{*}$ & $(0.093)$ & 0.01 & $(0.786)$ \\
\hline Constant & $-1.45^{* * *}(0.000)$ & $0.23^{* * *}(0.000)$ & $-1.92^{* * *}$ & $(0.003)$ & $0.09^{*}$ & $(0.061)$ \\
\hline Included Matches & $7-10$ & $7-10$ & $7-1$ & & $7-1$ & 10 \\
\hline Included Stages & $1-12$ & $1-12$ & $1-1$ & & $1-1$ & 12 \\
\hline M-S Dummies & Yes & Yes & $\mathrm{Ye}$ & & $\mathrm{Ye}$ & es \\
\hline Cluster VCE & Yes & Yes & Ye & & $\mathrm{Ye}$ & es \\
\hline
\end{tabular}

Table 15: Robustness check on the regression model. The baseline case is the strong commitment treatment. Specification 2 uses the same set of independent variables as the reported specification, 1, except uses a linear random-effects model. ${ }^{* * *} 1 \%,{ }^{* *} 5 \%,{ }^{*} 10 \%$ significance. 


\begin{tabular}{|c|c|c|c|c|c|c|c|}
\hline & \multirow[b]{2}{*}{ Machine } & \multicolumn{3}{|c|}{ Substitutes } & \multicolumn{3}{|c|}{ Complements } \\
\hline & & Strong & Unilateral & Bilateral & Strong & Unilateral & Bilateral \\
\hline Uncond. coop. & AAAA & 0.01 & 0.05 & 0.01 & 0.01 & 0.08 & 0.01 \\
\hline Cond. coop. & $\mathrm{ABC}(\mathrm{C} / \mathrm{D})$ & 0.19 & 0.13 & 0.16 & 0.11 & 0.23 & 0.18 \\
\hline Nash reversion & $\mathrm{ACCC}$ & 0.15 & 0.13 & 0.22 & 0.20 & 0.14 & 0.08 \\
\hline Part. coll. + Nash rev. & $\mathrm{BBCC}$ & 0.01 & 0.02 & 0.03 & 0.08 & 0.04 & 0.08 \\
\hline Nash & $\mathrm{CCCC}$ & 0.20 & 0.22 & 0.10 & 0.25 & 0.14 & 0.31 \\
\hline \multirow[t]{2}{*}{ Myopic best repsonse } & DCCC & 0.28 & 0.28 & 0.19 & & & \\
\hline & $\mathrm{BCCC}$ & & & & 0.29 & 0.21 & 0.25 \\
\hline Punishing & DDDD & 0.00 & 0.03 & 0.08 & 0.00 & 0.00 & 0.00 \\
\hline Other & $\longrightarrow$ & 0.14 & 0.13 & 0.19 & 0.06 & 0.13 & 0.09 \\
\hline
\end{tabular}

Table 16: Machine categorization: Distribution of machines in initial stages of matches 7-10 across treatments. For each category mentioned, machines (i) with Hamming distance at most 1 from the machine mentioned, (ii) that are not named explicitly in the second column (e.g. CCCC does not count towards DCCC) and (iii) do respond to collusion with the same action as the machine mentioned (e.g. ADDD does not count towards DDDD) are counted. Each machine is counted once and in case multiple categories apply, they are counted with equal weight in these categories. The category "Other" includes all machines satisfying none of the properties above.

\begin{tabular}{|c|c|c|c|c|c|c|c|}
\hline & \multirow[b]{2}{*}{ Machine } & \multicolumn{3}{|c|}{ Substitutes } & \multicolumn{3}{|c|}{ Complements } \\
\hline & & Strong & Unilateral & Bilateral & Strong & Unilateral & Bilateral \\
\hline Uncond. coop. & AAAA & $\begin{array}{c}0.77 \\
(17,1)\end{array}$ & $\begin{array}{l}0.06 \\
(6,3)\end{array}$ & $\begin{array}{c}0.46 \\
(17,2)\end{array}$ & $\begin{array}{l}0.58 \\
(7,1)\end{array}$ & $\begin{array}{l}0.02 \\
(2,2)\end{array}$ & $\begin{array}{l}0.71 \\
(5,1)\end{array}$ \\
\hline Cond. coop. & $\mathrm{ABC}(\mathrm{C} / \mathrm{D})$ & $\begin{array}{c}0.09 \\
(31,10)\end{array}$ & $\begin{array}{l}0.02 \\
(6,3)\end{array}$ & $\begin{array}{c}0.10 \\
(26,8)\end{array}$ & $\begin{array}{c}0.11 \\
(21,6)\end{array}$ & $\begin{array}{c}0.07 \\
(29,12)\end{array}$ & $\begin{array}{c}0.06 \\
(21,6)\end{array}$ \\
\hline Nash reversion & $\mathrm{ACCC}$ & $\begin{array}{c}0.06 \\
(17,7)\end{array}$ & $\begin{array}{l}0.05 \\
(8,5)\end{array}$ & $\begin{array}{c}0.04 \\
(14,6)\end{array}$ & $\begin{array}{l}0.01 \\
(3,3)\end{array}$ & $\begin{array}{l}0.03 \\
(8,5)\end{array}$ & $\begin{array}{l}0.03 \\
(3,2)\end{array}$ \\
\hline Part. coll. + Nash rev. & $\mathrm{BBCC}$ & $\begin{array}{l}0.07 \\
(1,1)\end{array}$ & $\begin{array}{l}0.00 \\
(0,0)\end{array}$ & $\begin{array}{l}0.04 \\
(1,1)\end{array}$ & $\begin{array}{c}0.11 \\
(17,2)\end{array}$ & $\begin{array}{l}0.14 \\
(3,2)\end{array}$ & $\begin{array}{l}0.05 \\
(5,3)\end{array}$ \\
\hline Nash & $\mathrm{CCCC}$ & $\begin{array}{c}0.13 \\
(43,6)\end{array}$ & $\begin{array}{c}0.06 \\
(22,8)\end{array}$ & $\begin{array}{l}0.01 \\
(2,2)\end{array}$ & $\begin{array}{l}0.02 \\
(8,2)\end{array}$ & $\begin{array}{l}0.01 \\
(2,2)\end{array}$ & $\begin{array}{c}0.06 \\
(32,5)\end{array}$ \\
\hline \multirow[t]{2}{*}{ Myopic best response } & DCCC & $\begin{array}{c}0.06 \\
(19,5)\end{array}$ & $\begin{array}{l}0.02 \\
(7,5)\end{array}$ & $\begin{array}{c}0.04 \\
(10,5)\end{array}$ & & & \\
\hline & $\mathrm{BCCC}$ & & & & $\begin{array}{c}0.03 \\
(13,3)\end{array}$ & $\begin{array}{c}0.04 \\
(12,6)\end{array}$ & $\begin{array}{c}0.43 \\
(14,5)\end{array}$ \\
\hline Pun. myopic best resp. & DCCD & $\begin{array}{l}0.03 \\
(2,1)\end{array}$ & $\begin{array}{l}0.00 \\
(0,0)\end{array}$ & $\begin{array}{l}0.08 \\
(6,3)\end{array}$ & $\begin{array}{l}0.00 \\
(0,0)\end{array}$ & $\begin{array}{l}0.00 \\
(0,0)\end{array}$ & $\begin{array}{l}0.00 \\
(0,0)\end{array}$ \\
\hline Punishing & DDDD & $\begin{array}{l}0.00 \\
(0,0)\end{array}$ & $\begin{array}{l}0.00 \\
(0,0)\end{array}$ & $\begin{array}{l}0.06 \\
(7,2)\end{array}$ & $\begin{array}{l}0.00 \\
(0,0)\end{array}$ & $\begin{array}{l}0.00 \\
(0,0)\end{array}$ & $\begin{array}{l}0.00 \\
(0,0)\end{array}$ \\
\hline
\end{tabular}

Table 17: Frequency of one-shot deviations conditional on the machine (matches 7-10; all stages). In parentheses, the total number of deviations and the number of distinct individuals deviating. 


\begin{tabular}{|c|c|c|c|c|c|c|}
\hline Treatment & Machine & Collusion & Dev.SC & Nash & Dev.SS & Total \\
\hline \multicolumn{7}{|l|}{ Substitutes } \\
\hline \multirow[t]{5}{*}{ Strong } & AAAA & 0.00 & 0.00 & 1.00 & 0.00 & $(17,1)$ \\
\hline & $\mathrm{ABC}(\mathrm{C} / \mathrm{D})$ & 0.52 & 0.03 & 0.29 & 0.16 & $(31,10)$ \\
\hline & $\mathrm{ACCC}$ & 0.24 & 0.00 & 0.06 & 0.71 & $(17,7)$ \\
\hline & $\mathrm{CCCC}$ & 0.81 & 0.09 & 0.00 & 0.09 & $(43,6)$ \\
\hline & DCCC & 0.53 & 0.21 & 0.00 & 0.26 & $(19,5)$ \\
\hline Unilateral & $\mathrm{CCCC}$ & 0.45 & 0.23 & 0.00 & 0.32 & $(22,8)$ \\
\hline \multirow[t]{2}{*}{ Bilateral } & AAAA & 0.00 & 0.00 & 0.24 & 0.76 & $(17,2)$ \\
\hline & $\mathrm{ABC}(\mathrm{C} / \mathrm{D})$ & 0.35 & 0.15 & 0.19 & 0.31 & $(26,8)$ \\
\hline \multicolumn{7}{|l|}{ Complements } \\
\hline \multirow[t]{2}{*}{ Strong } & $\mathrm{ABC}(\mathrm{C} / \mathrm{D})$ & 0.43 & 0.29 & 0.05 & 0.24 & $(21,6)$ \\
\hline & $\mathrm{BBCC}$ & 0.35 & 0.65 & 0.00 & 0.00 & $(17,2)$ \\
\hline Unilateral & $\mathrm{ABC}(\mathrm{C} / \mathrm{D})$ & 0.28 & 0.41 & 0.24 & 0.07 & $(29,12)$ \\
\hline \multirow[t]{2}{*}{ Bilateral } & $\mathrm{ABC}(\mathrm{C} / \mathrm{D})$ & 0.43 & 0.19 & 0.29 & 0.10 & $(21,6)$ \\
\hline & $\mathrm{CCCC}$ & 0.63 & 0.38 & 0.00 & 0.00 & $(32,5)$ \\
\hline
\end{tabular}

Table 18: Choice after a one-shot deviation at different prominent machines (matches 7-10; all stages). Machines with less than 15 one-shot deviations are not reported. In parentheses, the total number of deviations and the number of distinct individuals deviating.

\begin{tabular}{|c|c|c|c|}
\hline & Machine & Substitutes & Complements \\
\hline Uncond. coop. & AAAA & 0.05 & 0.04 \\
\hline Cond. coop. & $\mathrm{ABC}(\mathrm{C} / \mathrm{D})$ & 0.01 & 0.01 \\
\hline Nash reversion & $\mathrm{ACCC}$ & 0.02 & 0.01 \\
\hline Part. coll. + Nash rev. & $\mathrm{BBCC}$ & 0.02 & 0.09 \\
\hline Nash & $\mathrm{CCCC}$ & 0.03 & 0.00 \\
\hline \multirow{2}{*}{ Myopic best response } & $\mathrm{DCCC}$ & 0.03 & \\
\hline & $\mathrm{BCCC}$ & & 0.02 \\
\hline Punishing & DDDD & 0.06 & 0.00 \\
\hline
\end{tabular}

Table 19: Frequency of a machine modification for unilateral commitment variation conditional on machine (matches 7-10; all stages).

\begin{tabular}{|c|c|c|c|}
\hline & Machine & Substitutes & Complements \\
\hline Uncond. coop. & AAAA & 0.46 & 0.71 \\
\hline Cond. coop. & $\mathrm{ABC}(\mathrm{C} / \mathrm{D})$ & 0.02 & 0.00 \\
\hline Nash reversion & $\mathrm{ACCC}$ & 0.01 & 0.01 \\
\hline Part. coll. + Nash rev. & $\mathrm{BBCC}$ & 0.00 & 0.02 \\
\hline Nash & $\mathrm{CCCC}$ & 0.01 & 0.09 \\
\hline \multirow[t]{2}{*}{ Myopic best response } & DCCC & 0.03 & \\
\hline & $\mathrm{BCCC}$ & & 0.02 \\
\hline Punishing & DDDD & 0.03 & 0.00 \\
\hline
\end{tabular}

Table 20: Frequency of attempts to a machine modification for bilateral commitment variation conditional on machine (matches $7-10$; all stages). 


\begin{tabular}{|c|c|c|c|c|c|}
\hline \multirow[b]{2}{*}{ Treatment } & \multicolumn{2}{|c|}{ Previous stage outcome } & \multicolumn{2}{|c|}{ Machine modification } & \multirow[b]{2}{*}{ Total } \\
\hline & Label & Outcomes & From & To & \\
\hline \multicolumn{6}{|l|}{ Substitutes } \\
\hline \multirow[t]{5}{*}{ Unilateral } & Failed collusion & $(\mathrm{A}, \mathrm{B}),(\mathrm{B}, \mathrm{A})$ & - & - & - \\
\hline & Miscoordination & $(\mathrm{A}, \mathrm{C}),(\mathrm{A}, \mathrm{D}),(\mathrm{B}, \mathrm{C}),(\mathrm{B}, \mathrm{D})$ & AAAA & $\mathrm{CCCC}$ & $(3,2)$ \\
\hline & & $(\mathrm{A}, \mathrm{C}),(\mathrm{A}, \mathrm{D}),(\mathrm{B}, \mathrm{C}),(\mathrm{B}, \mathrm{D})$ & AAAA & DCCC & $(2,2)$ \\
\hline & Punishment path & $(\mathrm{C}, \mathrm{D}),(\mathrm{D}, \mathrm{C}),(\mathrm{D}, \mathrm{D})$ & $\mathrm{CCCC}$ & DDDD & $(2,2)$ \\
\hline & & & DDDD & $\mathrm{CCCC}$ & $(3,3)$ \\
\hline \multirow[t]{9}{*}{ Bilateral } & Failed collusion & $(\mathrm{A}, \mathrm{B}),(\mathrm{B}, \mathrm{A})$ & - & - & - \\
\hline & Miscoordination & $(\mathrm{A}, \mathrm{C}),(\mathrm{A}, \mathrm{D}),(\mathrm{B}, \mathrm{C}),(\mathrm{B}, \mathrm{D})$ & AAAA & - & $(11,3)$ \\
\hline & & & $\mathrm{ABCD}$ & - & $(3,2)$ \\
\hline & & & $\mathrm{ACCC}$ & - & $(3,3)$ \\
\hline & & & $\mathrm{BCCC}$ & - & $(3,2)$ \\
\hline & Punishment path & $(\mathrm{C}, \mathrm{D}),(\mathrm{D}, \mathrm{C}),(\mathrm{D}, \mathrm{D})$ & AAAA & - & $(11,3)$ \\
\hline & & & $\mathrm{ABCD}$ & - & $(5,4)$ \\
\hline & & & ACCD & - & $(6,3)$ \\
\hline & & & DDDD & - & $(5,4)$ \\
\hline \multicolumn{6}{|l|}{ Complements } \\
\hline \multirow[t]{3}{*}{ Unilateral } & Failed collusion & $(\mathrm{A}, \mathrm{B}),(\mathrm{B}, \mathrm{A})$ & - & - & - \\
\hline & Miscoordination & $(\mathrm{A}, \mathrm{C}),(\mathrm{A}, \mathrm{D}),(\mathrm{B}, \mathrm{C}),(\mathrm{B}, \mathrm{D})$ & AAAA & $\mathrm{CCCC}$ & $(3,2)$ \\
\hline & Punishment path & $(\mathrm{C}, \mathrm{D}),(\mathrm{D}, \mathrm{C}),(\mathrm{D}, \mathrm{D})$ & - & - & - \\
\hline \multirow[t]{4}{*}{ Bilateral } & Failed collusion & $(\mathrm{A}, \mathrm{B}),(\mathrm{B}, \mathrm{A})$ & - & - & - \\
\hline & Miscoordination & $(\mathrm{A}, \mathrm{C}),(\mathrm{A}, \mathrm{D}),(\mathrm{B}, \mathrm{C}),(\mathrm{B}, \mathrm{D})$ & $\mathrm{ABCD}$ & - & $(2,2)$ \\
\hline & & & $\mathrm{BBBB}$ & - & $(6,2)$ \\
\hline & Punishment path & $(\mathrm{C}, \mathrm{D}),(\mathrm{D}, \mathrm{C}),(\mathrm{D}, \mathrm{D})$ & - & - & - \\
\hline
\end{tabular}

Table 21: When and how machines are modified. Only prominent machines that were (attempted to be) modified by at least two different individuals for a given type of history during matches 4-10 are included. In the final column (total), the first number is the number of times the particular machine was (attempted to be) modified; the second number is the number of different individuals that contributed to that number.

\begin{tabular}{|c|c|c|c|c|c|c|c|c|c|}
\hline & & \multicolumn{4}{|c|}{ Substitutes } & \multicolumn{4}{|c|}{ Complements } \\
\hline & & $\mathrm{A}$ & B & $\mathrm{C}$ & $\mathrm{D}$ & $\mathrm{A}$ & B & $\mathrm{C}$ & $\mathrm{D}$ \\
\hline \multirow[t]{4}{*}{ Strong } & $\mathrm{A}$ & 0.40 & 0.05 & 0.24 & 0.31 & 0.33 & 0.35 & 0.28 & 0.03 \\
\hline & $\mathrm{B}$ & 0.03 & 0.24 & 0.68 & 0.05 & 0.01 & 0.21 & 0.74 & 0.03 \\
\hline & $\mathrm{C}$ & 0.02 & 0.06 & 0.83 & 0.08 & 0.00 & 0.05 & 0.89 & 0.05 \\
\hline & $\mathrm{D}$ & 0.04 & 0.06 & 0.68 & 0.22 & 0.01 & 0.02 & 0.91 & 0.06 \\
\hline \multirow[t]{4}{*}{ Unilateral } & $\mathrm{A}$ & 0.35 & 0.04 & 0.23 & 0.38 & 0.52 & 0.32 & 0.16 & 0.01 \\
\hline & $\mathrm{B}$ & 0.08 & 0.21 & 0.64 & 0.07 & 0.08 & 0.31 & 0.57 & 0.04 \\
\hline & $\mathrm{C}$ & 0.06 & 0.05 & 0.76 & 0.13 & 0.08 & 0.05 & 0.78 & 0.09 \\
\hline & $\mathrm{D}$ & 0.07 & 0.01 & 0.68 & 0.23 & 0.09 & 0.04 & 0.60 & 0.27 \\
\hline \multirow[t]{4}{*}{ Bilateral } & $\mathrm{A}$ & 0.48 & 0.01 & 0.15 & 0.33 & 0.30 & 0.35 & 0.31 & 0.03 \\
\hline & B & 0.03 & 0.25 & 0.57 & 0.15 & 0.01 & 0.33 & 0.65 & 0.02 \\
\hline & $\mathrm{C}$ & 0.03 & 0.06 & 0.73 & 0.17 & 0.01 & 0.05 & 0.87 & 0.07 \\
\hline & $\mathrm{D}$ & 0.05 & 0.04 & 0.55 & 0.37 & 0.02 & 0.03 & 0.80 & 0.15 \\
\hline
\end{tabular}

Table 22: Percent of machines in the initial stage (matches $7-10$ ) replying to $a_{-i}$ in the previous stage (rows) by $a_{i}$ in the current stage (columns). 